\title{
A MATLAB-Aided Method For Teaching Calculus-Based Business Mathematics
}

Jiajuan Liang, University of New Haven, USA

William S. Y. Pan, University of New Haven, USA

\begin{abstract}
MATLAB is a powerful package for numerical computation. MATLAB contains a rich pool of mathematical functions and provides flexible plotting functions for illustrating mathematical solutions. The course of calculus-based business mathematics consists of two major topics: 1) derivative and its applications in business; and 2) integration and its applications in business. Both topics involve various mathematical functions that may scare many business students. Fortunately, MATLAB provides an easy solution to handling the derivative and integration of various mathematical functions. With the help of MATLAB, all elementary formulas for derivative and integration in the textbooks of calculus-based business mathematics become less important to those students who have difficulty in learning and using mathematical formulas to find solutions to quantitative business problems. With the wide availability of various business data bases including the MATLAB package in the Samuel S. Bergami, Jr. Learning Center for Finance and Technology at the University of New Haven, in this paper, we illustrate how to use MATLAB to help students' learning of calculus-based business mathematics and apply the calculus principles to find solutions to real quantitative business problems. Our experience shows that MATLAB greatly saves students' efforts in learning difficult and pure calculus formulas and it is easy for business students to acquire the basic internal functions in using MATLAB.
\end{abstract}

\section{INTRODUCTION}

alculus-based business mathematics is a difficult course to many business students due to their poor algebraic skills. It is also challenging for instructors to teach this course within a limited time schedule, usually one-semester for covering derivative and integration topics, and a small part of multivariate calculus and applications in business. Without resorting to modern technology, traditional teaching of this course may be just presenting the formulas to students without proof, illustrating by examples and then having students do simple exercises by hand. This old-style teaching method may receive desirable effects if all students have the necessary preliminary algebra knowledge and algebra-operation skills. Many business students, however, show strong dislike in mathematical formulas. Some are even math-phobia when doing algebraic operations with relatively complicated mathematical functions by hand. It is a common situation that students in the same class have various levels of algebraic knowledge. When having students solve derivative or integration problems, after the instructor's illustrations of using the formulas, some students may be able to follow the same idea in the illustrated examples, but others have no idea in how to start with - they simply couldn't get the idea from the instructor's illustration. When facing with this situation, the instructor may either repeat the illustrations a few more times or make up the missing algebraic skills for those students in order to move on to the next topics. This may not be a problem if the teaching time is not limited. However, business mathematics is usually a one-semester course to business students and regular topics in derivative and integration and their applications in business are supposed to be covered. This calls for the resort of modern technology to help students' learning. Widely available and affordable computer programs make it possible for business students to learn calculus-based business mathematics with substantially reduced efforts, especially for those students with poor or weak math-operation skills.

Among the widely available symbolic computer programs such as MATHEMATICA, MATLAB and others, MATLAB may be one of the easiest one for business students to learn in short time. The Symbolic Math Toolbox in MATLAB provides almost all necessary math-operation techniques for students to the course of business 
mathematics. It is a quite direct approach to learning MATLAB commands for math operations in calculus, optimization and integration. In this paper, we will summarize our experience in using MATLAB to teach business mathematics for undergraduate students in the College of Business at the University of New Haven. Section 2 presents the step-by-step MATLAB-aided teaching topics in our one-semester course of business mathematics. Some concluding remarks are given in the last section.

\section{MATLAB-AIDED TEACHING TOPICS}

\subsection{Introduction to limit}

The major topics in calculus are based on the concept of limit. Most students learned this concept in high school but some of them forgot most of the mathematical operation in obtaining the limit. To proceed to the concept of instantaneous change rate or derivative of a function, it is necessary to review the concept of limit and show students how to obtain the limit of a given function. Because the topic of limit is transitory in teaching calculus, we just review the concept and show the students how to use MATLAB to obtain the limit of a given function. The following example covers the limits of frequently used functions such as polynomial functions, rational functions, root functions, composite power functions, exponential and logarithmic functions.

Example 2.1. Computing the limits.

(1) $\lim _{x \rightarrow 2}\left(x^{3}-2 x-1\right)$

(3) $\lim _{x \rightarrow 1}\left(\frac{x^{2}-1}{x-1}+\sqrt{x^{2}+3}\right)$

(5) $\lim _{t \rightarrow 10} 40\left(1-e^{-0.12 t}\right)$
(2) $\lim _{x \rightarrow 3}\left(\frac{x}{x+3}+\frac{x-3}{x^{2}-9}\right)$

(4) $\lim _{x \rightarrow 0}(1+2 x)^{1 / x}$

(6) $\lim _{x \rightarrow 2}[\ln (2 x-2)-\ln (x-1)]$

By using the "syms" and "limit" commands in MATLAB, the output can be obtained:

(1)

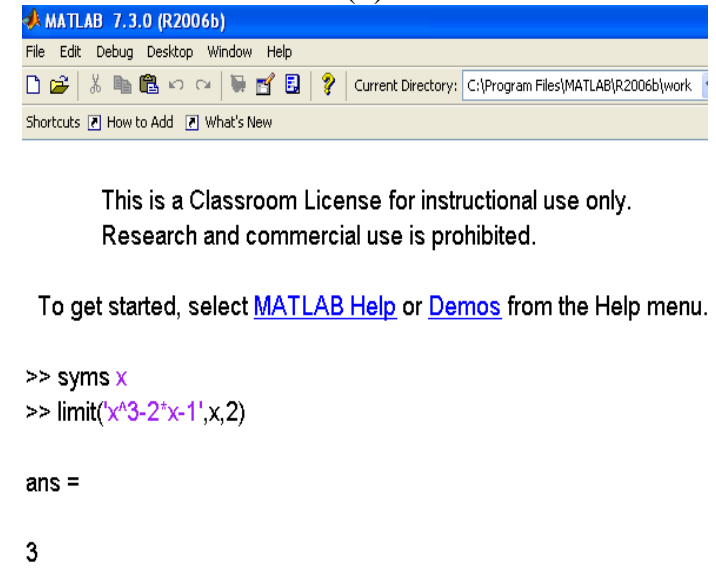

(2)

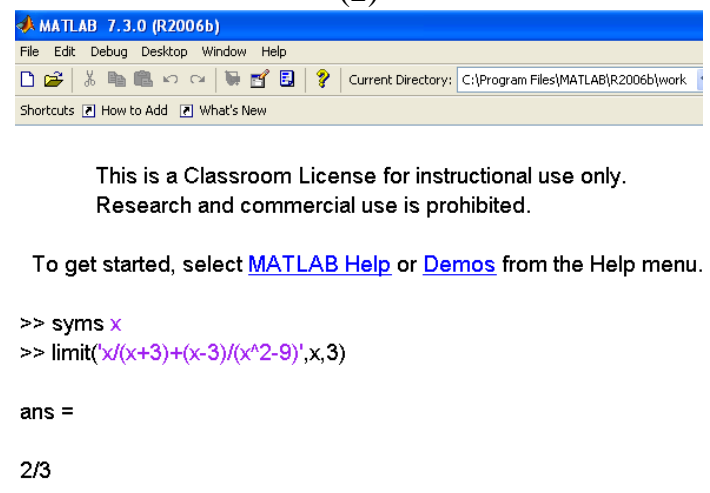


(3)

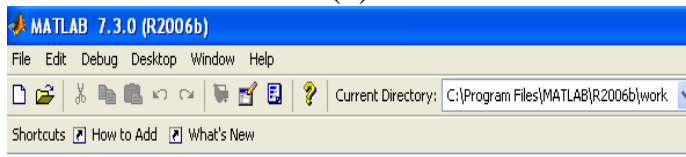

This is a Classroom License for instructional use only. Research and commercial use is prohibited.

To get started, select MATLAB Help or Demos from the Help menu.

$\gg$ syms $x$

$>\operatorname{limit}\left(\left(x^{A} 2-1\right) /(x-1)+\operatorname{sqrt}\left(x^{A} 2+3\right)^{\prime}, x, 1\right)$

ans $=$

4

\section{(5)}

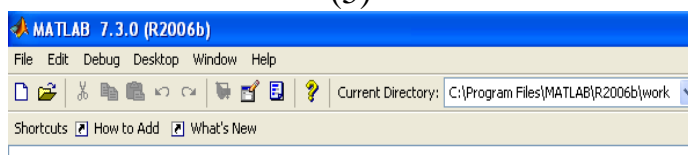

This is a Classroom License for instructional use only. Research and commercial use is prohibited.

To get started, select MATLAB Help or Demos from the Help menu.

$>$ syms t

$>\operatorname{limit}\left(\left(40^{\star}\left(1-\exp \left(-0.12^{\star} t\right)\right)^{\prime}, t, 10\right)\right.$

ans $=$

27.952231523511916134200895716671
(4)

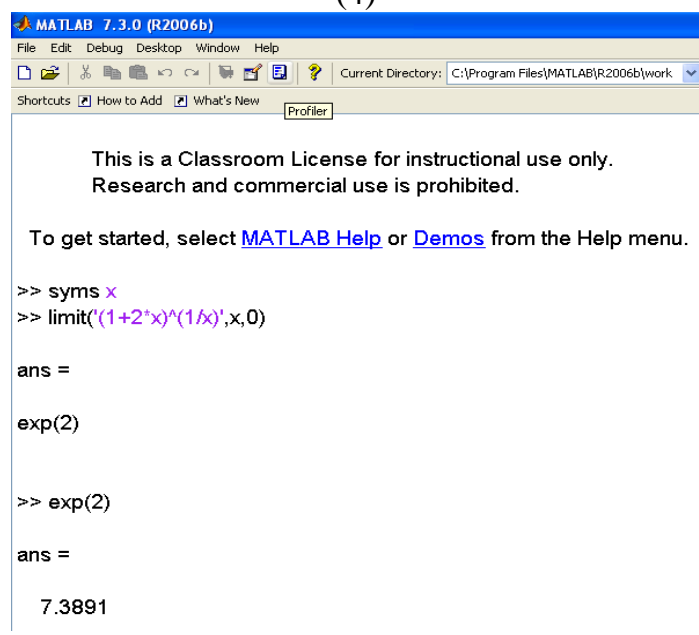

(6)

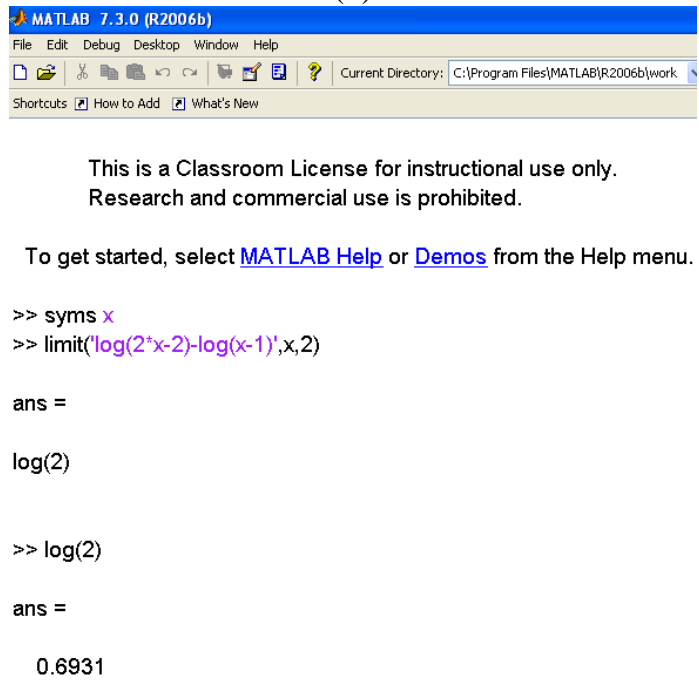

\subsection{Graphing and its application}

Graphing is an intuitive and the easiest way for students to understand the numerical relationship between two variables or to compare the increasing and decreasing rates of two or more functions simultaneously. The instantaneous change rate of derivative of a function can be easily interpreted by graphing.

Example 2.2. Using the graphing technique in identifying the optimal business strategy.

(1) A company manufactures and sells $x$ transistors per week. The weekly cost and price-demand equation are given by 
Cost function: $C(x)=90,000+30 x, \quad 0 \leq x \leq 9,000$,

And the price function: $p=300-\frac{x}{30}$. Identify the approximate optimal demand $x$ to maximize the profit.

The profit function is obtained:

$P(x)=$ Revenue - Cost $=$

$x p-C(x)=x\left(300-\frac{x}{30}\right)-(90,000+30 x)=-\frac{x^{2}}{30}+270 x-90,000, \quad 0 \leq x \leq 9,000$.

By using the "ezplot" command in MATLAB, the output is obtained. It can be easily identified that the approximate optimal demand $x$ to maximize the profit is close to 4,000 transistors.

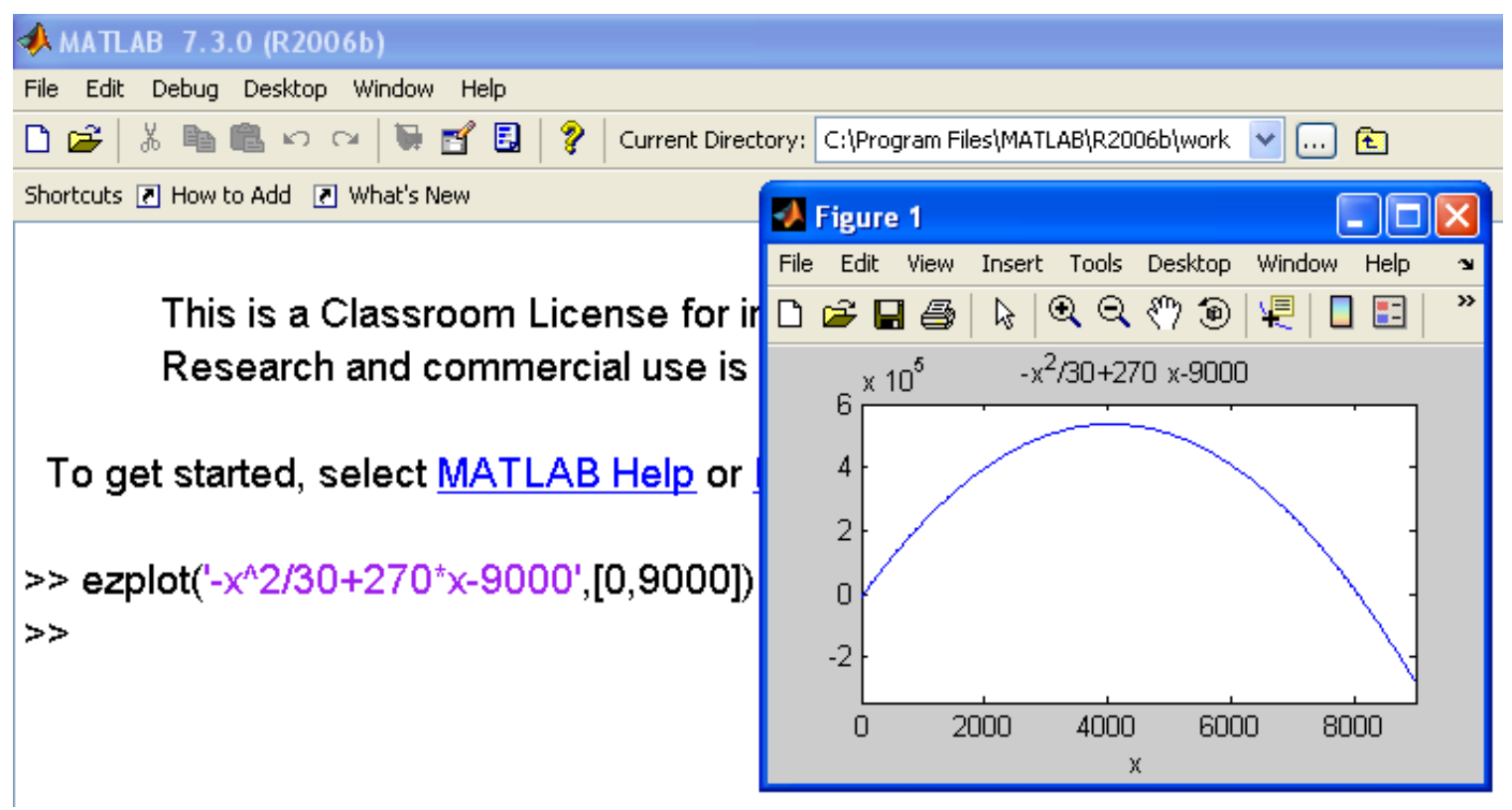

Figure 1. Plot of the profit function versus the demand level

(2) A mail-order company specializing in computer equipment estimated (based on past data) the price-demand equation

$p=\exp (5.4474-0.0008 x), \quad 200 \leq x \leq 900$

Where $x$ is the weekly demand for $\mathrm{x}$ modems with unit price $\$ 100$. Identify the approximate optimal demand $x$ to maximize the profit.

The profit function is obtained:

$P(x)=$ Revenue - Cost $=x \exp (5.4474-0.0008 x)-100 x, \quad 200 \leq x \leq 900$.

By using the "ezplot" command in MATLAB, the output is obtained. It can be easily identified that the approximate optimal demand $x$ to maximize the profit is close to 450 modems. 


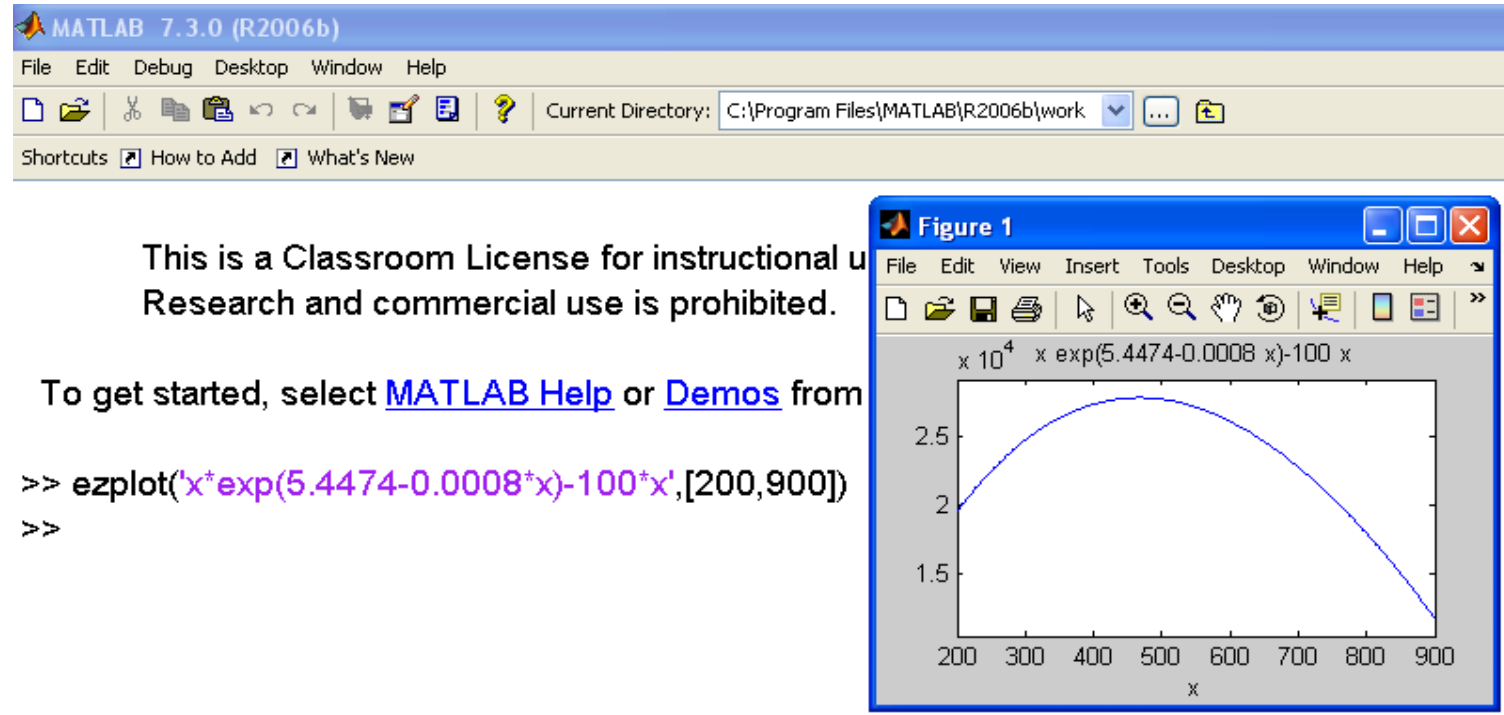

Figure 2. Plot of the profit function versus the demand level

(3) A department store estimated the (based on past data) the price-demand equation for selling $x$ cream puffs as

$p=6.2242-0.5238 \ln (x), \quad 5,000 \leq x \leq 10,000$.

Assume the unit cost for making a cream puff is $\$ 1$. Identify the approximate optimal demand $x$ to maximize the profit.

The profit function is obtained:

$P(x)=$ Revenue - Cost $=x(6.2242-0.5238 \ln (x))-x, \quad 5,000 \leq x \leq 10,000$.

By using the "ezplot" command in MATLAB, the output is obtained. It can be easily identified that the approximate optimal demand $x$ to maximize the profit is close to 8,000 cream puffs.

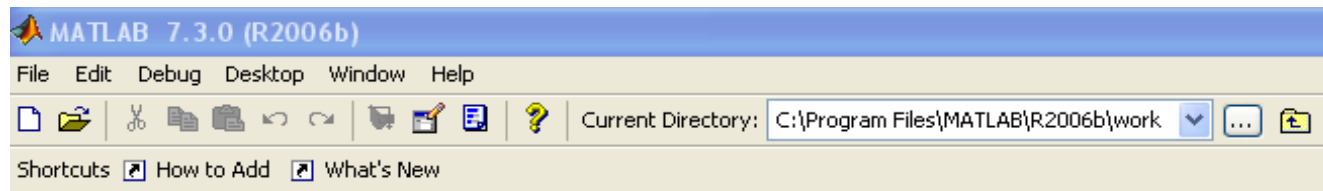

This is a Classroom License for instructional use only.

Research and commercial use is prohibited.

To get started, select MATLAB Help or Demos from

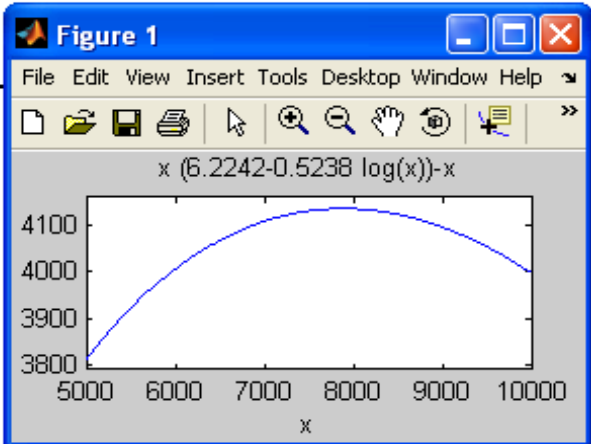

Figure 3. Plot of the profit function versus the demand level 
Example 2.3. Graphing two or more functions in a single window. Use the graphing technique to identify the demand interval in which profit can be made. When the revenue is greater than the cost, profit can be made. Therefore, it is necessary to plot the revenue function and cost function in a single window for comparison between the two functions.

In (1) of Example 2.2, the two functions are:

Revenue function : $R(x)=x\left(300-\frac{x}{30}\right)$, Cost function : $C(x)=90,000+30 x, \quad 0 \leq x \leq 9,000$.

The "plot" command in MATLAB is used to plot two or more functions in a single window. This command requires generating the plotting points first before plotting. The MATLAB steps are given as in the following output.

Step 1. Generate the plotting values for $x$. Under the MATLAB command sign, type " $\mathrm{x}=[0: 10: 9000]$;", where " 0 " is the starting point of the plot and " 9000 " the ending point, " 10 " is the step length which is chosen by convenience;

Step 2. Generate the plotting values for $C(x)$ by the given cost function by typing " $\mathrm{C}=90000+30 *$; " under the MATLAB command line, here the semi-colon ";"; is typed to avoid any output from the command;

Step 3. Generate the plotting values for $R(x)$ by the given revenue function by typing " $\mathrm{R}=\mathrm{x} .{ }^{*}(300-\mathrm{x} / 30)$;" under the MATLAB command line, where the "dot product" " .*" is used for product of vectors because $x=[0: 10: 9000]$ is a vector of $1 \times 900$;

Step 4. After generating the plotting values, it is ready to plot by using the "plot" command. In the "plot" command, "x,R,'-" means that the plot for $R(x)$ versus $x$ is a "real line", "x, $\mathrm{C}$, , - " means that the plot for $C(x)$ versus $x$ is a "dashed line". MATLAB provides several options for the types of line;

Step 5. Use the "gtext" command to add a label to the curves for $R(x)$ and $C(x)$, respectively. This step is just optional. Type "gtext( '...')" under the MATLAB command line for whatever text “...” you want to label.

Step 6. Find the break-even points (zero profit): the revenue is equal to the cost so that zero profit is obtained by using the "solve" command in MATLAB to solve the equation " $R(x)=C(x)$ ", which gives two solutions

$x_{1}=4050-150 \times 609^{1 / 2} \approx 348$ and $x_{2}=4050+150 \times 609^{1 / 2} \approx 7752$.

Conclusion: when the demand level is $348<x<7752$, it makes positive profit. Otherwise, it results in negative profit. The break-even demand levels are $x=348$ and $x=7752$, where zero profit is obtained. 


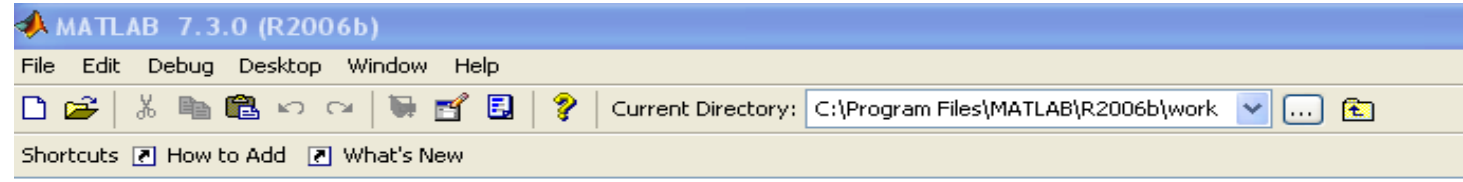

This is a Classroom License for instructional use only. Research and commercial use is prohibited.

To get started, select MATLAB Help or Demos from the Help menu.
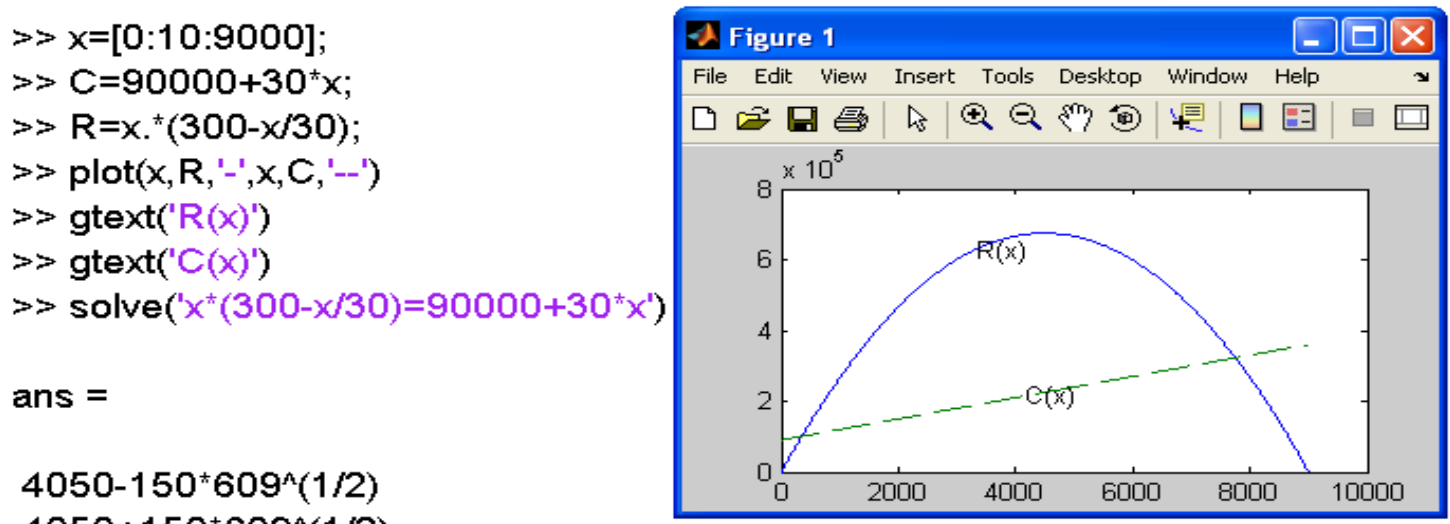

Figure 4. Plot of the revenue function and cost function versus the demand level

(2) In (2) of Example 2.2, the two functions are:

Revenue function : $R(x)=x p=x \exp (5.4474-0.0008 x)$,

Cost function : $C(x)=100 x, \quad 200 \leq x \leq 900$.

By following the same steps as above, the MATLAB output is given as follows. It is clear tat the break-even solutions are $x_{1}=0$ and $x_{2} \approx 1053$.

Conclusion: when the demand level is $0<x<1053$, it makes positive profit. Otherwise, it results in negative profit. The break-even demand levels are $x=0$ and $x=1053$, where zero profit is obtained. 


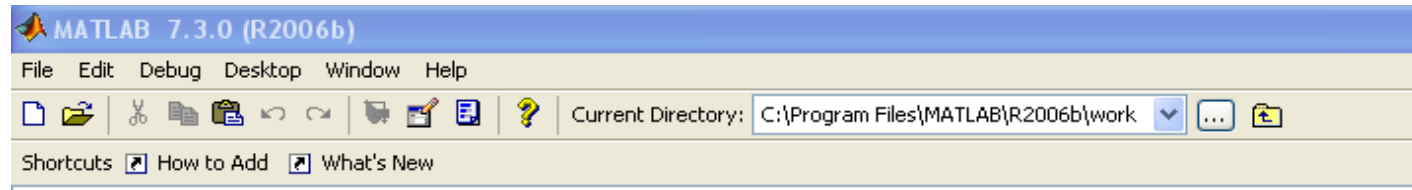

This is a Classroom License for instructional use only.

Research and commercial use is prohibited.

To get started, select MATLAB Help or Demos from the Help menu.

$>x=[200: 10: 1600]$

$\gg \mathrm{C}=100^{+} \mathrm{x}$

$>\mathrm{R}=\mathrm{x} .{ }^{\star} \exp \left(5.4474-0.0008^{*} \mathrm{x}\right)$;

$>\operatorname{plot}\left(x, R,{ }^{\prime}-', x, C,{ }^{\prime}-{ }^{\prime}\right)$

$>$ gtext('R( $\left.(x)^{\prime}\right)$

$\gg$ gtext(' $\mathrm{C}(\mathrm{x})$ ')

$>$ solve $\left(x^{*} \exp \left(5.4474-0.0008^{+} x\right)=100^{\star} x^{\prime}\right)$

ans $=$

0.

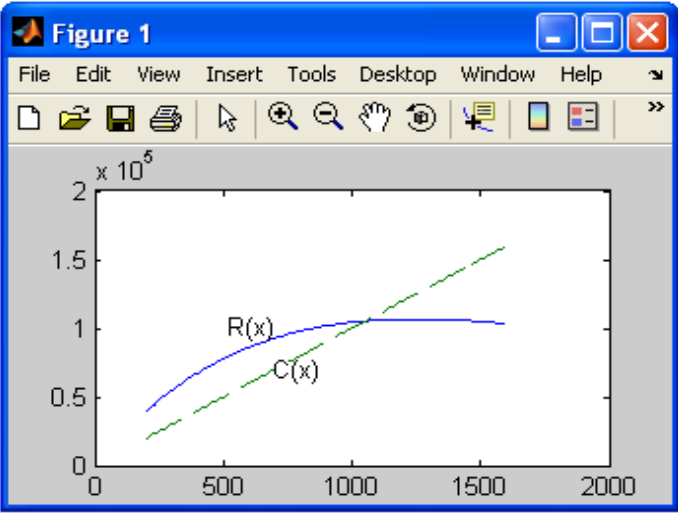

1052.7872675148857899550213632891

Figure 5. Plot of the revenue function and cost function versus the demand level

(3) In (3) of Example 2.2, the two functions are:

Revenue function: $R(x)=x p=x(6.2242-0.5238 \ln (x))$,

Cost function : $C(x)=x, \quad 5,000 \leq x \leq 10,000$.

By following the same steps as above, the MATLAB output is given as follows. It is clear tat the break-even solution is $x \approx 21,454$.

Conclusion: when the demand level is $x<21,454$, it makes positive profit. Otherwise, it results in negative profit. The break-even demand level is $x=21,454$, where zero profit is obtained. 


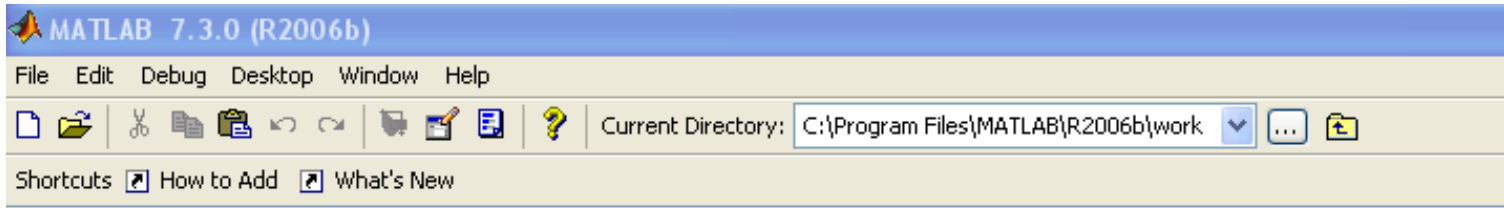

This is a Classroom License for instructional use only. Research and commercial use is prohibited.

To get started, select MATLAB Help or Demos from the Help menu.

$$
\begin{aligned}
& >x=[5000: 10: 30000] \\
& \gg \mathrm{C}=\mathrm{x} \text {; } \\
& >\mathrm{R}=\mathrm{x} .{ }^{*}\left(6.2242-0.5238^{\star} \log (x)\right) \text {; } \\
& >\operatorname{plot}\left(x, R,{ }^{\prime}-', x, C, \text {,--') }^{\prime}\right. \\
& >\text { gtext('R( }(x) \text { ') } \\
& >\text { gtext( }\left(\mathrm{C}(\mathrm{x})^{\prime}\right) \\
& >\text { solve }\left({ }^{*} x^{*}\left(6.2242-0.5238^{*} \log (x)\right)=x^{\prime}\right)
\end{aligned}
$$

ans $=$

\subsection{8}

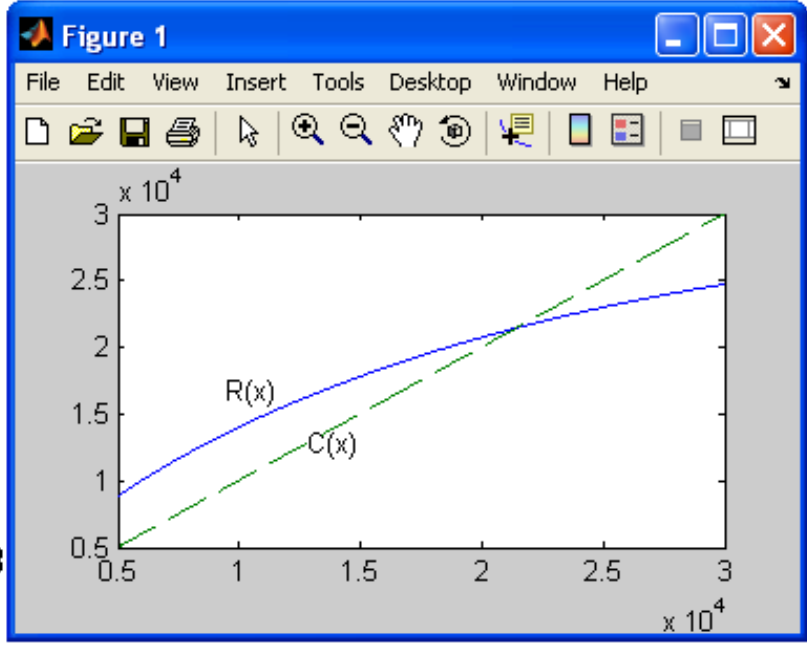

Figure 6. Plot of the revenue function and cost function versus the demand level

\subsection{Derivative and optimization}

\subsubsection{The first derivative and its application in business}

Derivative is the major topic in teaching calculus-based business mathematics. The major application of calculus in business is to find the optimal solution to a quantitative business problem. This is solved by optimization process based on derivative. Therefore, derivative is the key to solve many quantitative business problems related to optimization. In widely available textbooks on business mathematics, a common way to handle the derivative topic is to illustrate by various examples how to use the formulas to obtain the derivative of a given function. Without resorting to modern computer programs, this method may work for students with sufficient algebra-operation skills. Business students are usually more interested in finding solutions to business problems without preparing themselves in basic mathematical theory. Resorting to modern computer programs such as MATLAB with less emphasis on manual operation makes it possible for students to realize this purpose. By using MATLAB, most students realized that it is a lot of fun instead of burden to study business mathematics with the help of MATLAB. We illustrate the use of MATLAB in teaching derivative topics through the following example.

Example 2.4. Price-supply and price-demand problems.

(1) The number of $x$ stereo speakers a retail chain is willing to sell per week at a price of $\$ p$ is given by

$x=80 \sqrt{p+25}-40, \quad 20 \leq p \leq 100$. 
Find the derivative $x^{\prime}(p)=\frac{d x}{d p}$ and $x^{\prime}(75)$, and interpret the result.

(2) The number of $y$ stereo speakers people are willing to buy per week from a retail chain at a price of $\$ p$ is given by

$y=1000-60 \sqrt{p+25}, \quad 20 \leq p \leq 100$.

Find the derivative $y^{\prime}(p)=\frac{d y}{d p}$ and $y^{\prime}(75)$, and interpret the result.

(3) What is the common number of stereo speakers that retail chain is willing to sell and people are willing to buy per week?

The solutions are given by MATLAB output in Figure 7 as follows.

(1) Derivative computation

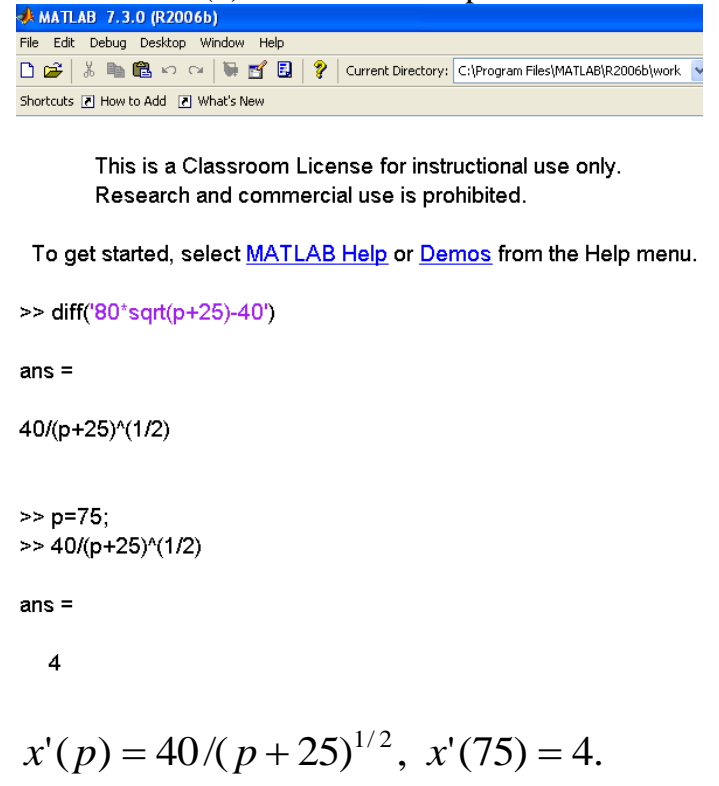

Figure 7a
(2) Derivative computation

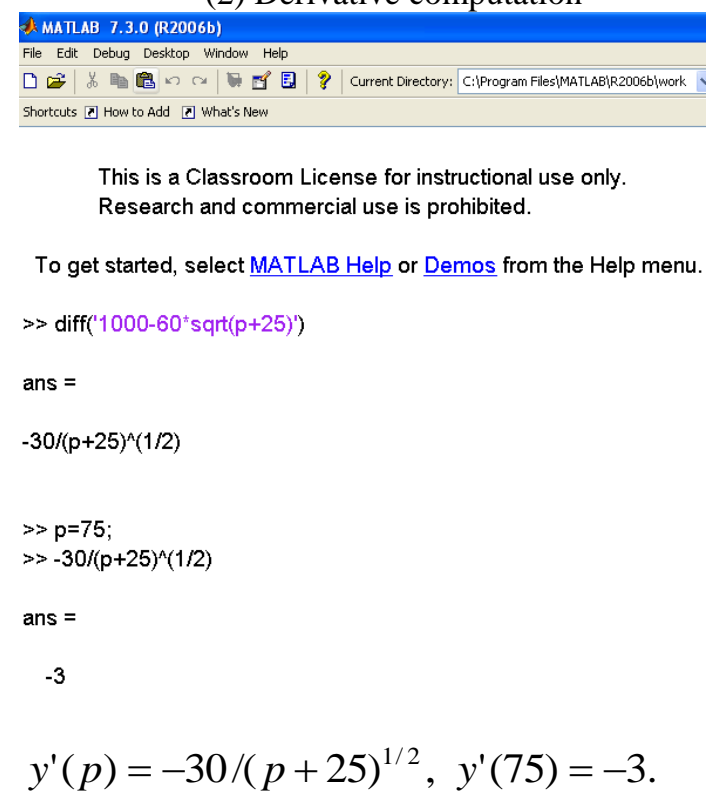

Figure $7 b$ 


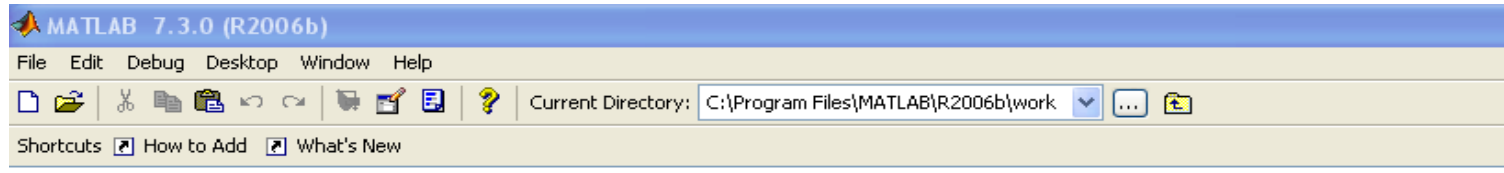

This is a Classroom License for instructional use only.

Research and commercial use is prohibited.

To get started, select MATLAB Help or Demos from the Help menu.

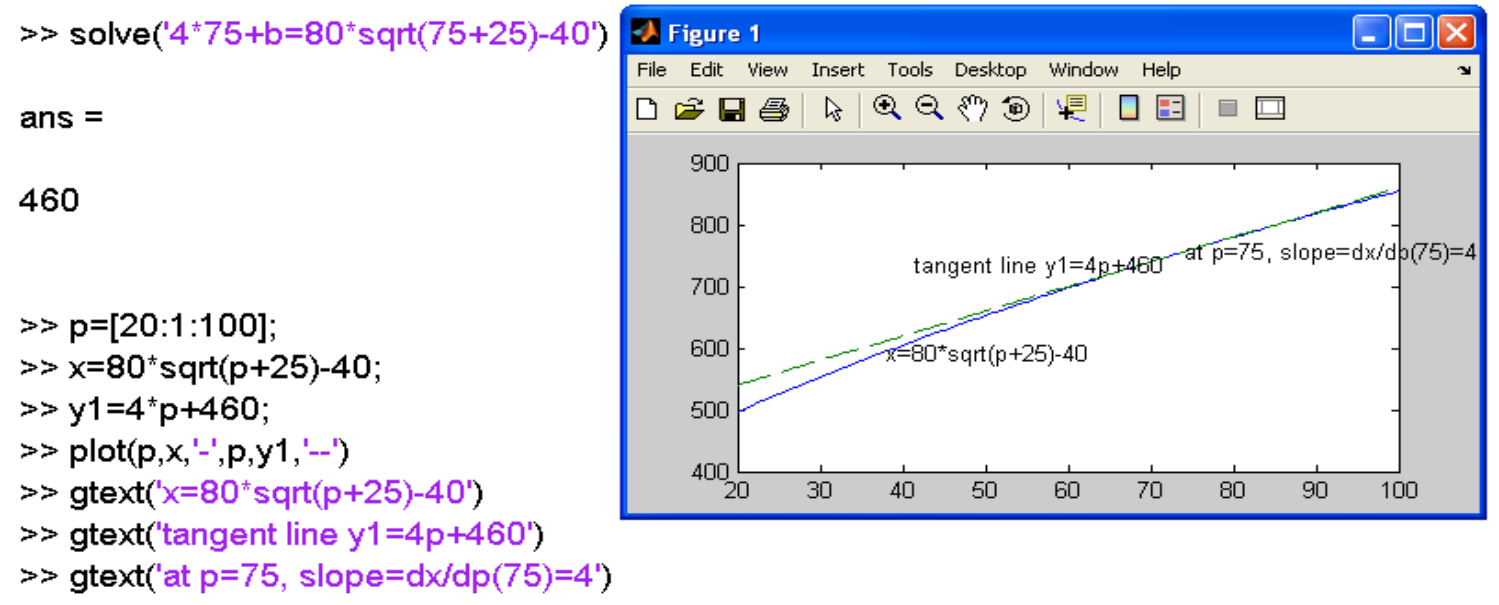

$\rightarrow$

Figure 7c Interpretation of $x^{\prime}(75)=4$

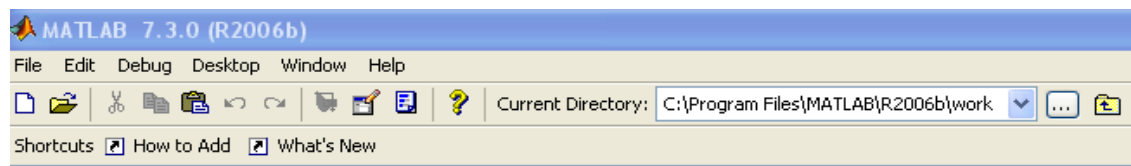

This is a Classroom License for instructional use only.

Research and commercial use is prohibited.

To get started, select MATLAB Help or Demos from the Help menu.

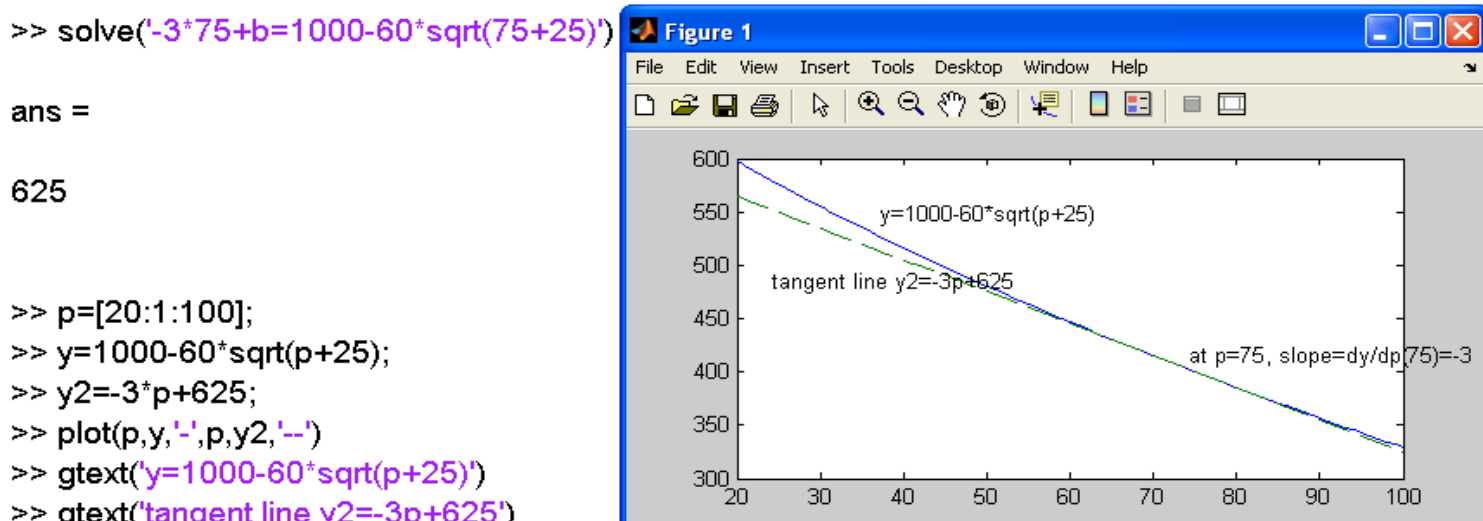

$>$ gtext('tangent line $y 2=-3 p+625$ ')

$>$ gtext('at $p=75$, slope $=\operatorname{dy} / d p(75)=-3$ ')

Figure 7d Interpretation of $y^{\prime}(75)=-3$ 
(3) the common number of stereo speakers that retail chain is willing to sell and people are willing to buy per week is the intersection point of the curve for $x=80 \sqrt{p+25}-40$ and the curve for $y=1000-60 \sqrt{p+25}$. That is,

$$
80 \sqrt{p+25}-40=1000-60 \sqrt{p+25}
$$

Which gives the solution $x=y \approx 554$ stereo speakers at the common price $p=1479 / 49 \approx \$ 30.18$ per unit.

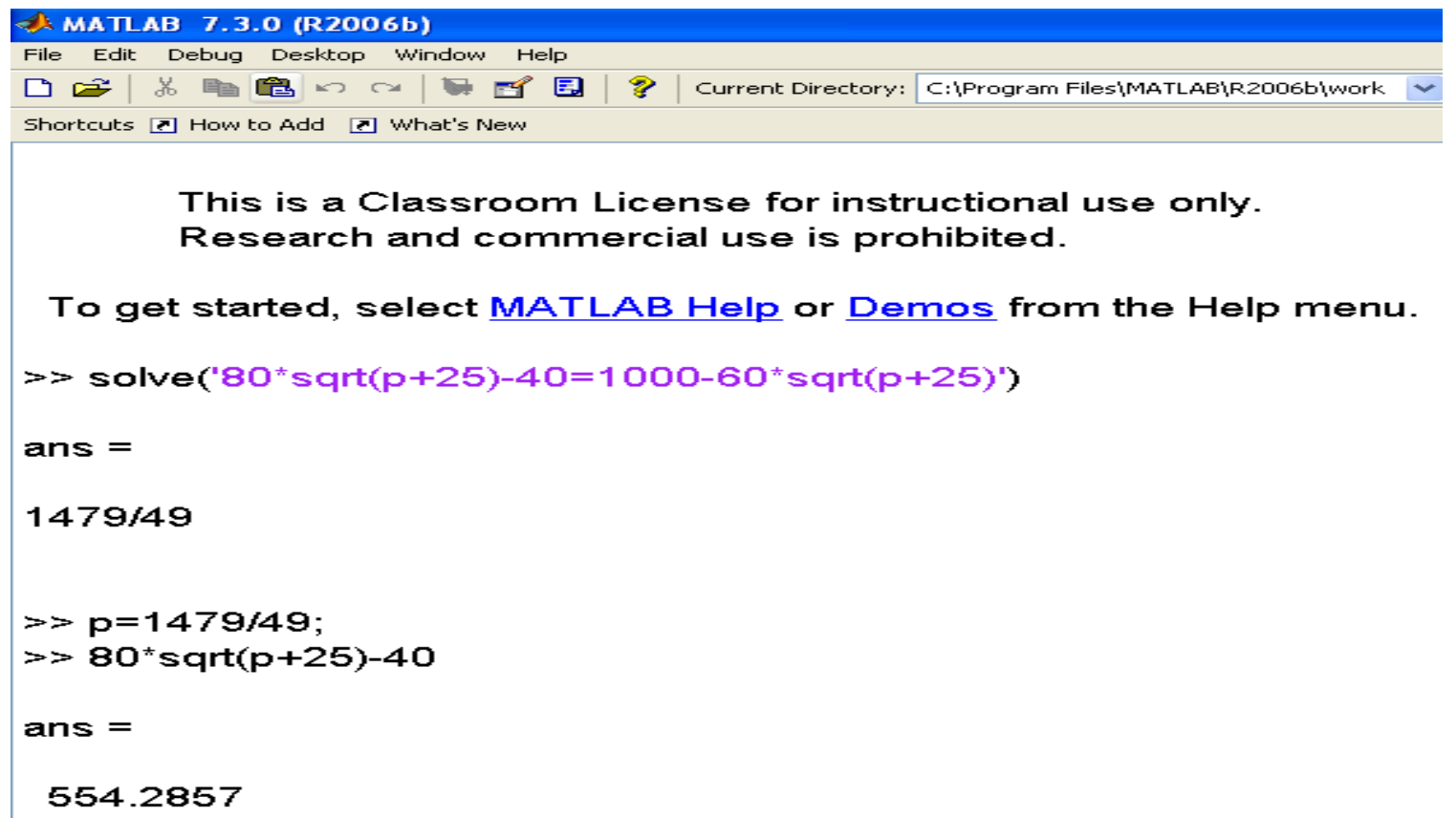

Figure 7e MATLAB Computation of the common price and the common number of stereo speakers that retail chain is willing to sell and people are willing to buy per week

Example 2.5. (Example 2.2 continues) Maximizing profit, marginal analysis in business and economics. Find the marginal profit and the best demand to maximize the profit for the profit functions in Example 2.2.

(1) The profit function is:

$P(x)=x\left(300-\frac{x}{30}\right)-(90,000+30 x), \quad 0 \leq x \leq 9,000$.

Marginal profit is the derivative $P^{\prime}(x)$, and the best demand satisfies $P^{\prime}(x)=0$. The results are given in the MATLAB output in Figure 8, which gives $P^{\prime}(x)=270-\frac{x}{15}$, and the best demand $x=4050$ that satisfies $P^{\prime}(x)=0$. Figure 1 in Example 2.2 shows that $x=4050$ really leads to the maximum profit. 


\begin{tabular}{|c|c|c|c|c|c|c|}
\hline File Edit & Debug Desktop $v$ & ndow Help & & & & \\
\hline पथ & 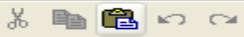 & 뵤요 国 & ? & Current Directory: & C:'YProgram Files'MMATLAB',R2006b'work & 2 \\
\hline \multicolumn{7}{|c|}{ Shortcuts $]$ How to Add What's New } \\
\hline
\end{tabular}

This is a Classroom License for instructional use only. Research and commercial use is prohibited.

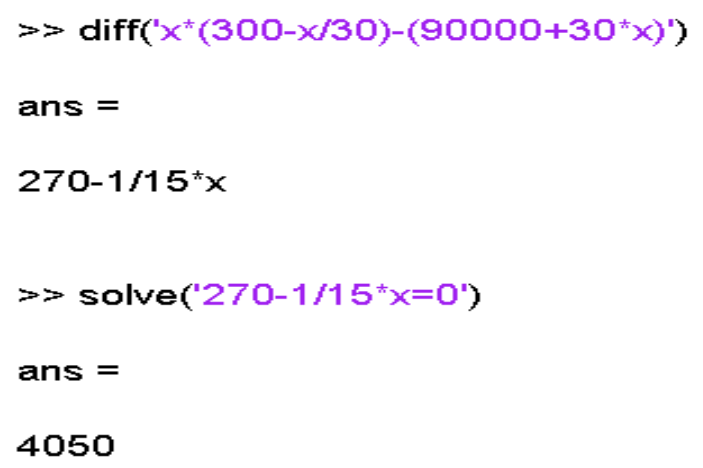

Figure 8. MATLAB computation of marginal profit and the best demand to maximize the profit

(2) The profit function is:

$P(x)=x \exp (5.4474-0.0008 x)-100 x, \quad 200 \leq x \leq 900$.

The results are given in the MATLAB output in Figure 9, which gives the marginal profit $P^{\prime}(x)=\exp (5.4474-0.0008 x)-0.0008 x \exp (5.4474-0.0008 x)-100$, and the best demand $x=467$ that satisfies $P^{\prime}(x)=0$. Figure 2 in Example 2.2 shows that $x=467$ really lead to the maximum profit.

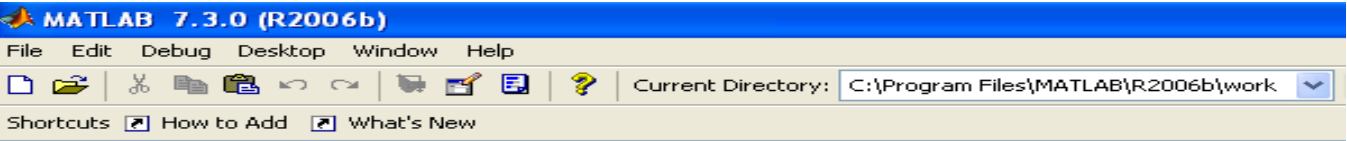

This is a Classroom License for instructional use only. Research and commercial use is prohibited.

To get started, select MATLAB Help or Demos from the Help menu. $\Rightarrow>\operatorname{diff}\left(x^{*} \exp \left(5.4474-0.0008^{*} x\right)-100^{*} x^{\prime}\right)$

ans $=$

$\exp \left(5.4474-.8 e-3^{*} x\right)-.8 e-3^{*} x^{*} \exp \left(5.4474-.8 e-3^{*} x\right)-100$

$\Rightarrow>$ solve $\left(\exp \left(5.4474-.8 e-3^{*} x\right)-.8 e-3^{*} x^{*} \exp \left(5.4474-.8 e-3^{*} x\right)-100=0^{\prime}\right)$

ans $=$

467.41573463086774660112793277537

Figure 9. MATLAB computation of marginal profit and the best demand to maximize the profit 
(3) The profit function is:

$P(x)=x(6.2242-0.5238 \ln (x))-x, \quad 5,000 \leq x \leq 10,000$.

The results are given in the MATLAB output in Figure 9, which gives the marginal profit $P^{\prime}(x)=4.7004-0.5238 \ln (x)$, and the best demand $x=7892$ that satisfies $P^{\prime}(x)=0$. Figure 3 in Example 2.2 shows that $x=7892$ really leads to the maximum profit.

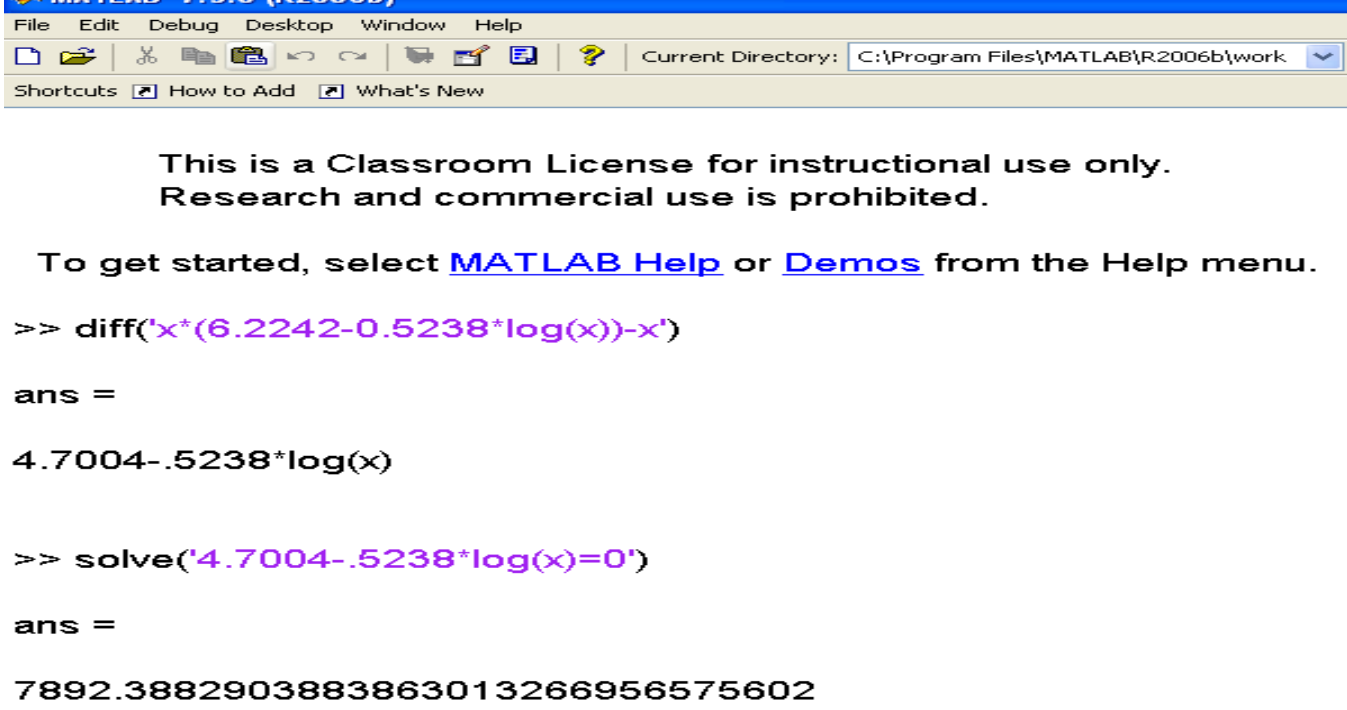

Figure 10. MATLAB computation of marginal profit and the best demand to maximize the profit

\subsubsection{The second derivative and its application}

The major application of the second derivative in business is to confirm whether the optimal solution to the problem by the first derivative method leads to maximum or minimum. This requires checking the sign of the second derivative at the optimal point(s). A negative value of the second derivative at an optimal point confirms that this optimal point is a local maxima; a positive value of the second derivative at an optimal point confirms that this optimal point is a local minima. Usually speaking, a local optimal solution is also the absolute optimal solution to a business problem.

Example 2.6. Example 2.5 continues.

(1) In Example 2.5, the optimal solution to the profit function is $x=4050$. The computation of the second derivative of the profit function at this point is given in Figure 11, which is a negative constant. This confirms that $x=4050$ is a local maxima. This implies that the optimal demand level is $x=4050$. 


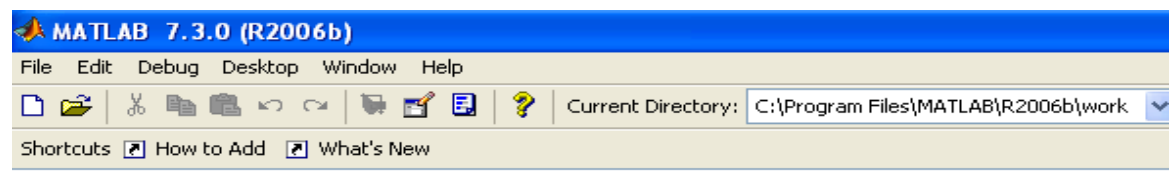

This is a Classroom License for instructional use only. Research and commercial use is prohibited.

To get started, select MATLAB Help or Demos from the Help menu.

$>\operatorname{diff}\left(x^{\star}(300-x / 30)-\left(90000+30^{*} x\right)^{\prime}, 2\right)$

ans $=$

$-1 / 15$

Figure 11. Computation of the second derivative of the profit function

(2) In Example 2.5, the optimal solution to the profit function is $x=467$. The computation of the second derivative of the profit function at this point is given in Figure 12.

$P^{\prime \prime}(x)=-0.0016 \exp (5.4474-0.0008 x)+0.64 \times 10^{-6} x \exp (5.4474-0.0008 x)$

And $P^{\prime \prime}(467)=-0.2079<0$. This confirms that $x=467$ is a local maxima. This implies that the optimal demand level is $x=467$.

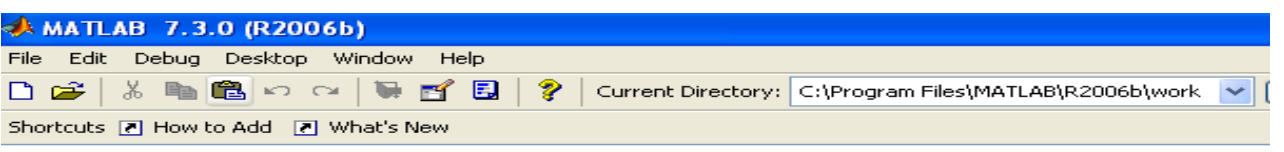

This is a Classroom License for instructional use only.

Research and commercial use is prohibited.

To get started, select MATLAB Help or Demos from the Help menu.

$>\operatorname{diff}\left(x^{\star} \exp \left(5.4474-0.0008^{*} x\right)-100^{*} x^{\prime}, 2\right)$

ans $=$

$-.16 e-2^{*} \exp \left(5.4474-.8 e-3^{*} x\right)+.64 e-6^{*} x^{*} \exp \left(5.4474-.8 e-3^{*} x\right)$

$>>x=467$

$>-.16 e-2^{*} \exp \left(5.4474-.8 e-3^{*} x\right)+.64 e-6^{*} x^{*} \exp \left(5.4474-.8 e-3^{*} x\right)$

ans $=$

$-0.2079$

Figure 12. Computation of the second derivative of the profit function

(3) In Example 2.5, the optimal solution to the profit function is $x=7892$. The computation of the second derivative of the profit function at this point is given in Figure 12. $P^{\prime \prime}(x)=-0.5238 / x$ and 
$P^{\prime \prime}(7892)=-6.6371 \times 10^{-5}<0$. This confirms that $x=7892$ is a local maxima. This implies that the optimal demand level is $x=7892$.

\begin{tabular}{|c|c|c|c|c|c|c|}
\hline File Edit & Debug Desktop & Window Help & & & & \\
\hline 口 & 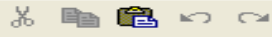 & 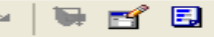 & ? & Current Directory: & C:'Program Files'MATLAB'R2006biwork & 2 \\
\hline
\end{tabular}

This is a Classroom License for instructional use only. Research and commercial use is prohibited.

To get started, select MATLAB Help or Demos from the Help menu.

$>>\operatorname{diff}\left(x^{*}\left(6.2242-0.5238^{*} \log (x)\right)-x^{\prime}, 2\right)$

$\operatorname{ans}=$

$-.5238 / x$

$>>x=7892$

$>-.5238 k$

$\operatorname{ans}=$

$-6.6371 e-005$

Figure 13. Computation of the second derivative of the profit function

\subsection{Integration and its applications in business}

Integration may be the most challenging topic in teaching calculus-based business mathematics for both instructors and students. Traditional teaching of this topic is usually by presenting the formulas and illustrating the application of the formulas through various examples. This again requires students' even stronger algebra-operation skills. It is just these skills that make it the most difficult topic for students to learn integration. Integration consists of indefinite integrals and definite integrals. While the idea for both indefinite and definite integrals is usually easy for business students to understand, manual computation of the indefinite and definite integrals is completely another story for many students. Based on our experience, MATLAB makes it possible for business students to learn the integration topic and apply it to business problems without much difficulty.

Example 2.7. Revenue analysis. The weekly marginal revenue from the sales of $x$ pairs of tennis shoes is given by

$$
R^{\prime}(x)=40-0.02 x+\frac{200}{x+1}, \quad R(0)=0,
$$

Where $R(x)$ is the revenue in dollars. Find the revenue function and the revenue from the sale of 1,000 pairs of tennis shoes.

The MATLAB solution is given in Figure 14, where the first command gives the indefinite integral

$$
R(x)=\int\left(40-0.02 x+\frac{200}{x+1}\right) d x=40 x-0.01 x^{2}+200 \ln (x+1)+C
$$


( $\mathrm{C}$ does not appear in the MATLAB output). The second command is for identifying the constant $\mathrm{C}$ from the initial condition $R(0)=0$, which gives $\mathrm{C}=0$. So the final solution is

$$
R(x)=\int\left(40-0.02 x+\frac{200}{x+1}\right) d x=40 x-0.01 x^{2}+200 \ln (x+1) \text { with } R(0)=0
$$

It is easy to obtain

$$
R(1000)=40(1000)-0.01(1000)^{2}+200 \ln (1000+1)=\$ 31,382
$$

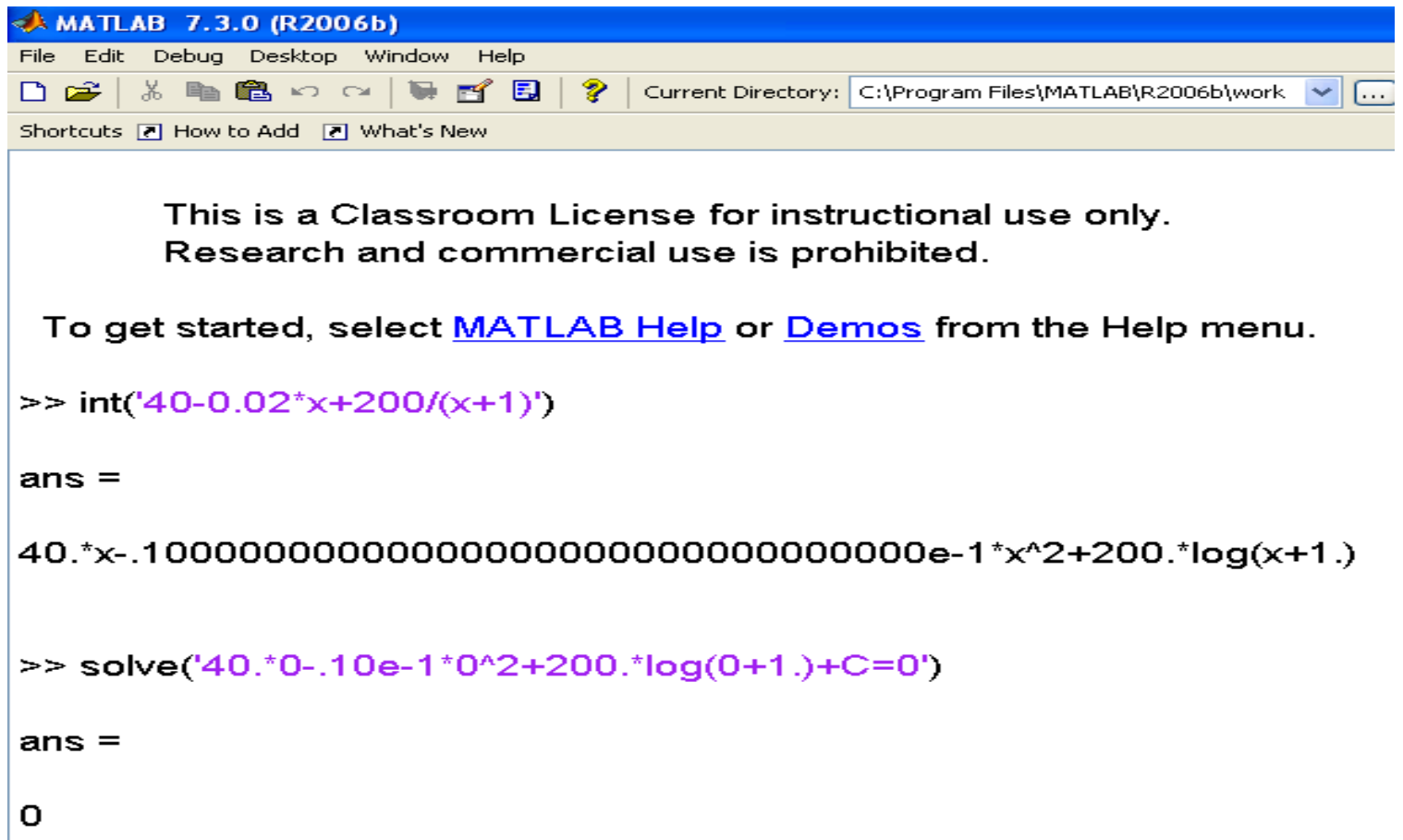

This is a Classroom License for instructional use only.

Research and commercial use is prohibited.

To get started, select MATLAB Help or Demos from the Help menu.

Figure 14. Computation of indefinite integral with a given initial condition

Example 2.8. Marketing analysis. An automobile company is ready to introduce a new line of cars with a national sales campaign. After test marketing the line in a carefully selected city, the marketing research department estimates that sales (in millions of dollars) will increase at the rate of

$$
S^{\prime}(t)=10-10 e^{-0.1 t}, \quad 0 \leq t \leq 24
$$

t months after the national campaign has started.

(1) What will be the total sales, $S(t)$, t months after the beginning of the national campaign if assuming zero sales at the beginning of the campaign?

(2) What are the estimated total sales for the first 12 months of the campaign?

(3) When will the estimated total sales reach $\$ 100$ million? 
The same steps as in Example 2.7 are followed and the MATLAB output for (1) is given in Figure 15a. It shows that

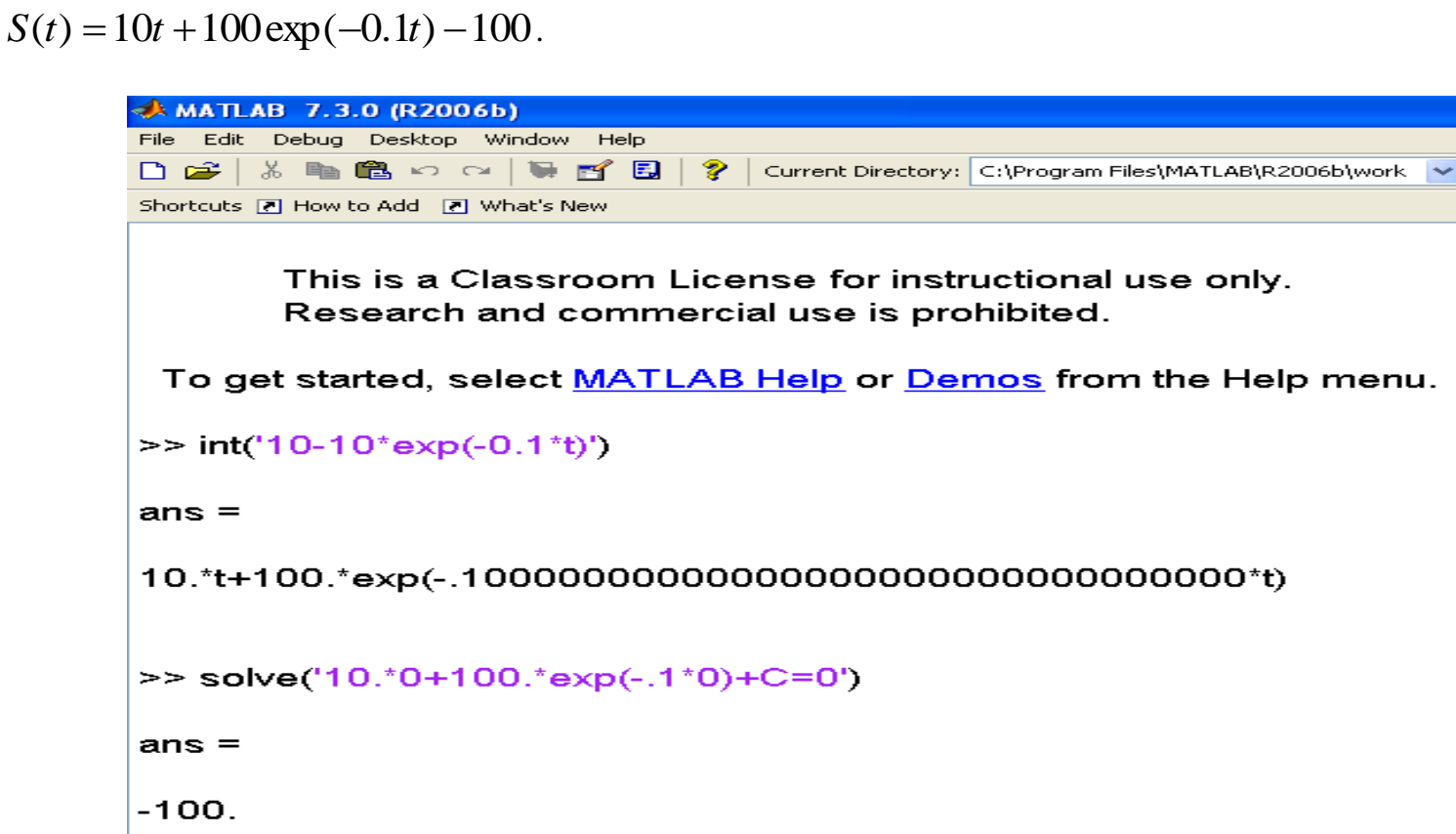

Figure 15a Computation of the indefinite integral with a given initial condition

Results for (2) and (3) are given in Figure 15b, where for (3), it is required to solve the equation for t: $S(t)=10 t+100 \exp (-0.1 t)-100=100$.

It shows that $S(12)=50.1194$ million dollars and it will take about 18.4 months to reach the total sales of $\$ 100$ million (the negative solution does not apply).

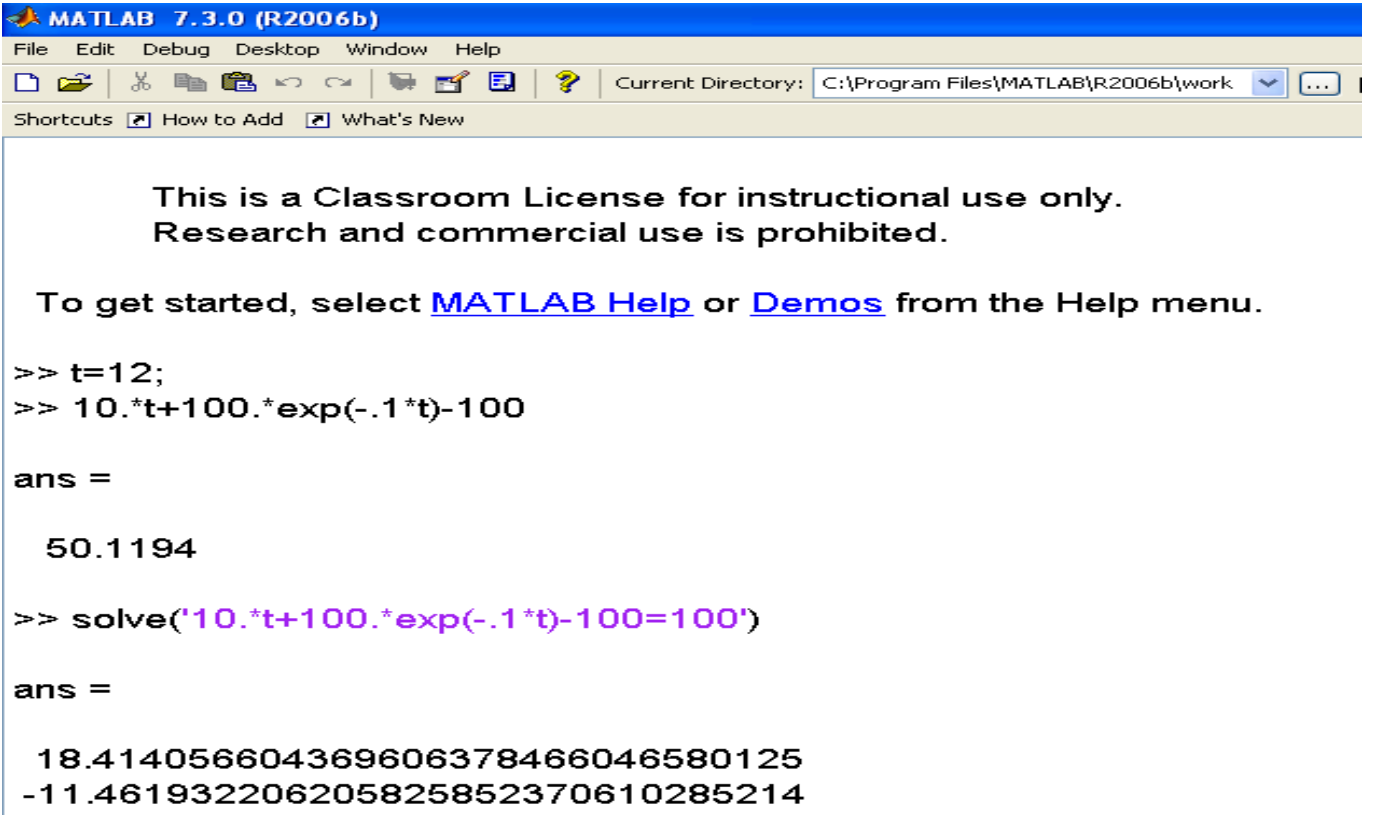

Figure 15b MATLAB solution to (2) and (3) in Example 2.8 
Example 2.9. Consumers' and producers' surplus, equilibrium price and equilibrium quantity. These are the important concepts in business.

If $(\bar{x}, \bar{p})$ is a point from the price-demand equation $p=D(x)$ for a particular product, the consumers' surplus (CS) at a price level $\bar{p}(\bar{p}=D(\bar{x}))$ is defined by

$C S=\int_{0}^{\bar{x}}[D(x)-\bar{p}] d x$.

CS represents the total savings to consumers who are willing to pay more than $\bar{p}$ but are still able to buy the product at the price $\bar{p}$.

If $(\bar{x}, \bar{p})$ is a point from the price-supply equation $p=S(x)$ for a particular product, the producers' surplus (PS) at a price level $\bar{p}(\bar{p}=S(\bar{x}))$ is defined by

$P S=\int_{0}^{\bar{x}}[\bar{p}-S(x)] d x$.

PS represents the total savings to producers who are willing to supply units at a lower than $\bar{p}$ but are still able to supply units at the price $\bar{p}$.

If $p=D(x)$ and $p=S(x)$ are the price-demand and price-supply equations, respectively, for a product, and if $(\bar{x}, \bar{p})$ is the point of intersection of these two equations, $\bar{p}$ is called the equilibrium price and $\bar{x}$ (where $\bar{p}=D(\bar{x})=S(\bar{x})$ ) the equilibrium quantity.

(1) The price-demand equation is given by $p=D(x)=9-\ln (x+4)$. Find the consumers' surplus at the price level $\bar{p}=\$ 2.089$;

(2) The price-supply equation is given by $p=S(x)=5 \ln (x+1)$. Find the producers' surplus at the price level $\bar{p}=\$ 25$;

(3) Find the equilibrium price and the equilibrium quantity.

The MATLAB solutions are given in Figure 16 (a, b, c). Figure 16a is for solution of (1), the first command "solve('2.089=9- $\left.\ln (\mathrm{x}+4)^{\prime}\right)$ " is for finding $\bar{x}$ so that $2.089=\bar{p}=D(\bar{x})=9-\ln (\bar{x}+4)$. It shows that $\bar{x} \approx 999.25$. The second command "int(' $9-\ln (\mathrm{x}+4)-2.089$ ',0,999.25)" is for computing the consumers' surplus

$C S=\int_{0}^{\bar{x}}[D(x)-\bar{p}] d x=\int_{0}^{999.25}[9-\ln (x+4)-2.089] d x=977.15$.

This means that the consumers' surplus is $\$ 977.15$. It represents the total savings $\$ 977.15$ to consumers who are willing to pay more than the price $\$ 2.089$ but are still able to buy the product at the price $\$ 2.089$. 


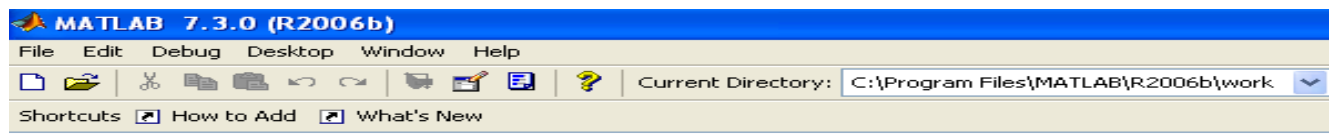

This is a Classroom License for instructional use only. Research and commercial use is prohibited.

To get started, select MATLAB Help or Demos from the Help menu. $>>$ solve('2.089=9-log $(x+4) ')$

ans $=$

999.24999082324610099399634909241

$>>\operatorname{int}($ '9-log $(x+4)-2.089$ ',0,999.25)

$\operatorname{ans}=$

977.15116826772562149933040020657

Figure 16a. MATLAB solution to (1) of Example 2.9

Figure $16 \mathrm{~b}$ is for solution of (2), the first command "solve( $25=5 * \ln (\mathrm{x}+1)$ ')" is for finding $\bar{x}$ so that $25=\bar{p}=S(\bar{x})=5 \ln (\bar{x}+1)$. It shows that $\bar{x}=\exp (5)-1 \approx 147$. The second command "int('25$\left.5 * \ln (\mathrm{x}+1)^{\prime}, 0,147\right)^{\prime \prime}$ is for computing the producers' surplus

$P S=\int_{0}^{\bar{x}}[\bar{p}-S(x)] d x=\int_{0}^{147}[25-5 \ln (x+1)] d x=712.06$.

This means that the producers' surplus is $\$ 712.06$. It represents the total savings $\$ 712.06$ to producers who are willing to supply at a lower price than $\$ 25$ but are still able to supply the product at the price $\$ 25$.

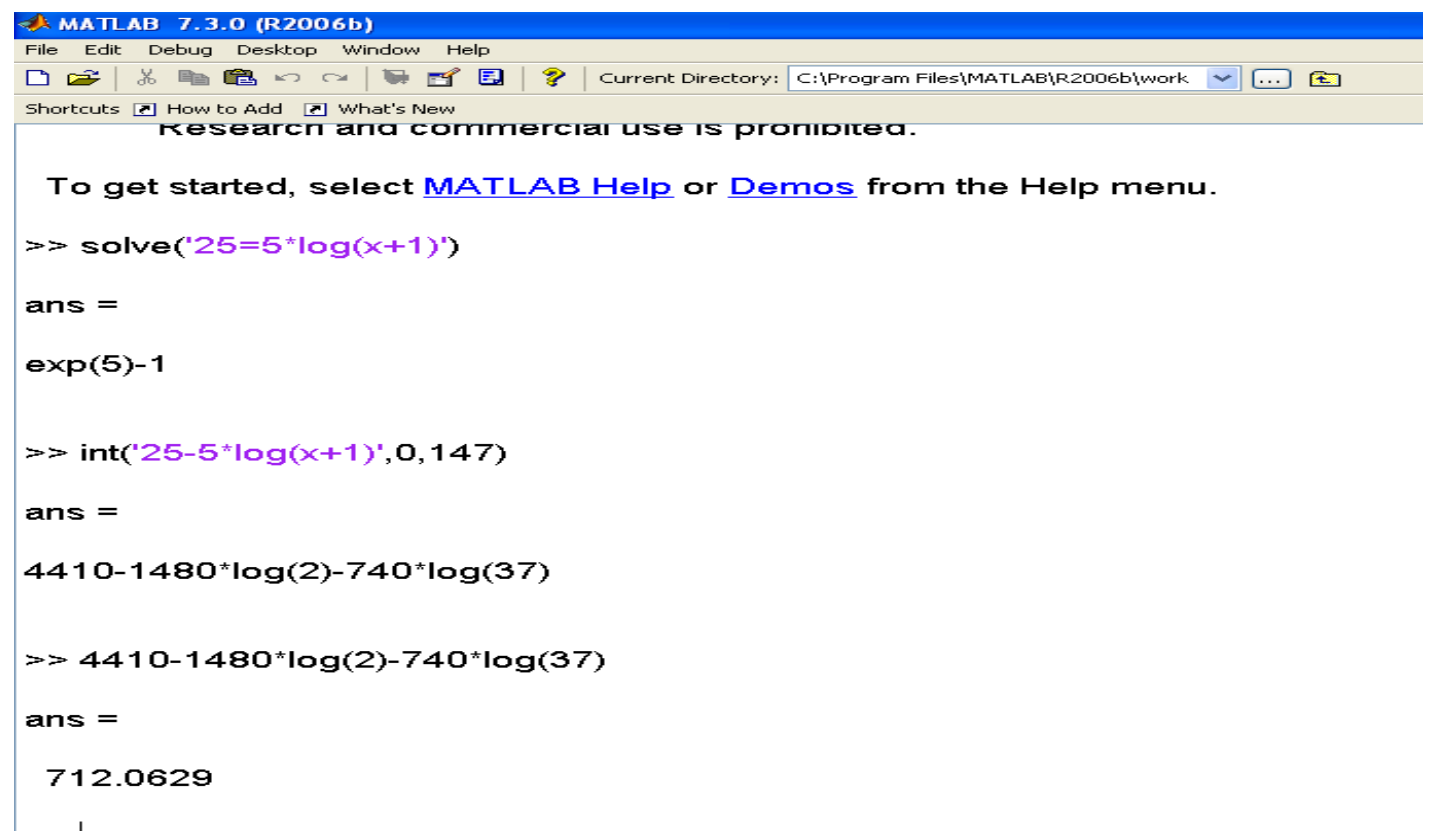

Figure 16b. MATLAB solution to (2) of Example 2.9 
Figure 16c is for solution of (3), the first command "solve $\left({ }^{9} 9-\log (\mathrm{x}+4)=5 * \log (\mathrm{x}+1)\right.$ ')" is for finding the equilibrium quantity $\bar{x}$ so that $D(\bar{x})=9-\ln (x+4)=S(\bar{x})=5 \ln (\bar{x}+1)$. It shows that $\bar{x} \approx 3$. The equilibrium price $\bar{p}=9-\ln (3.09+4) \approx \$ 7.04$ per unit.

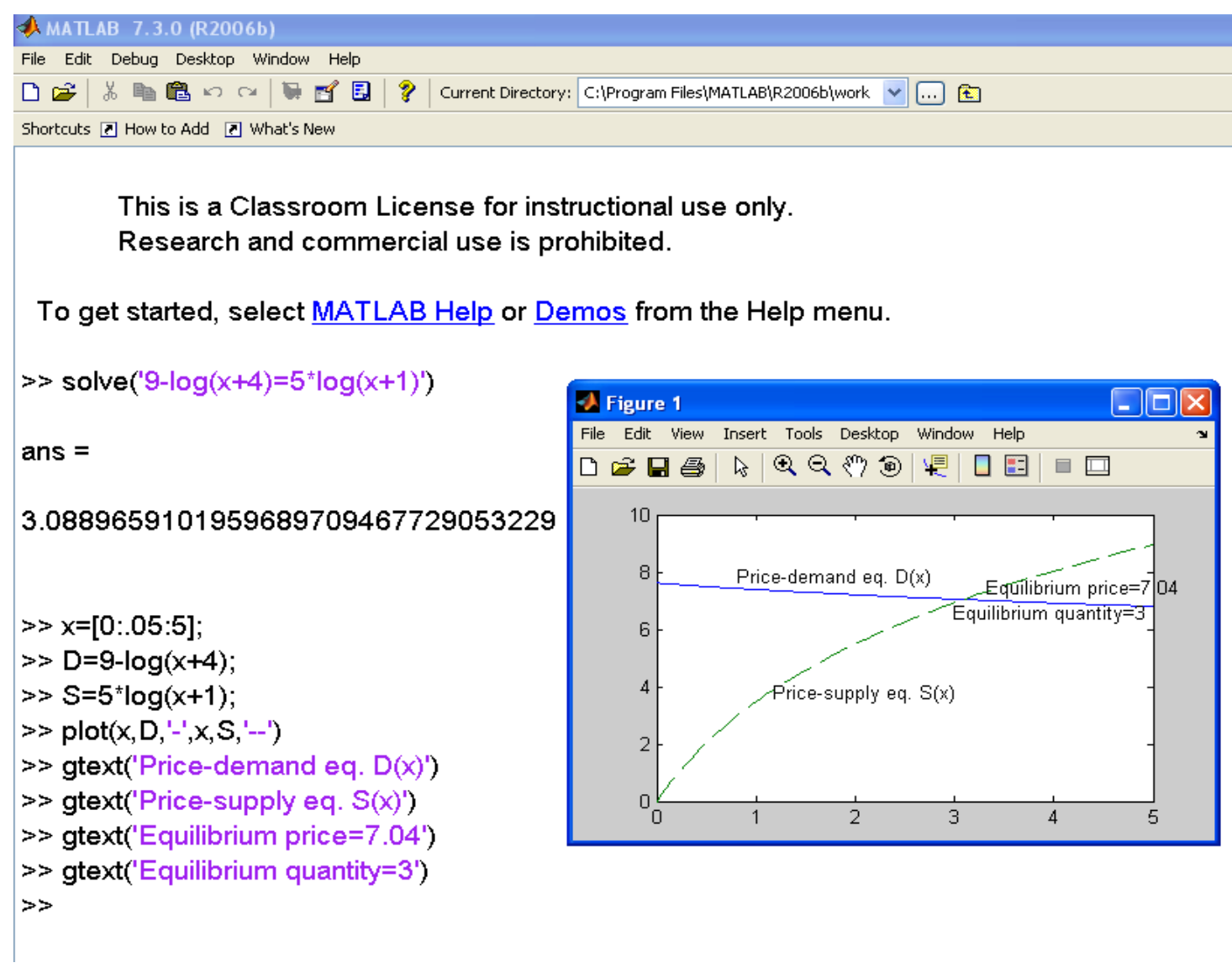

Figure 16c. MATLAB solution to (3) of Example 2.9

\subsection{Introduction to multivariate calculus}

Functions of more than one variable are frequently encountered in quantitative business problems. For example, if a company produces two types of products $(x, y)$ and each type of products usually has a price-demand equation, say, $p=p(x, y)$ and $q=q(x, y)$, then the revenue from the two types of products is a two-variable function

$$
R(x, y)=x p(x, y)+y q(x, y)
$$

If the cost function is given as $C(x, y)$, then the profit function is also a two-variable function

$$
P(x, y)=x p(x, y)+y q(x, y)-C(x, y)
$$

If the company wants to maximize its profit based on its available resources, it leads a maximization problem on the two-variable profit function $P(x, y)$. This can be easily extended to the cases of three or more 
variables if the company produces more than one type of products. Problems related to maximization of multivariate profit functions belong to the topic of multivariate calculus. In this section we will illustrate the MATLAB solutions to some simple multivariate calculus problems.

\subsubsection{Graphing a two-variable function}

Example 2.10. Plotting the two functions:

(1) $z=f(x, y)=e^{-x-y^{2}}=\exp \left(-x^{2}-y^{2}\right), \quad-3 \leq x \leq 3, \quad-3 \leq y \leq 3$;

(2) $z=f(x, y)=x e^{-x-y^{2}}=x \exp \left(-x^{2}-y^{2}\right), \quad-3 \leq x \leq 3, \quad-3 \leq y \leq 3$.

The MATLAB solutions to (1) and (2) are given in Figure 17a and Figure 17b, respectively.

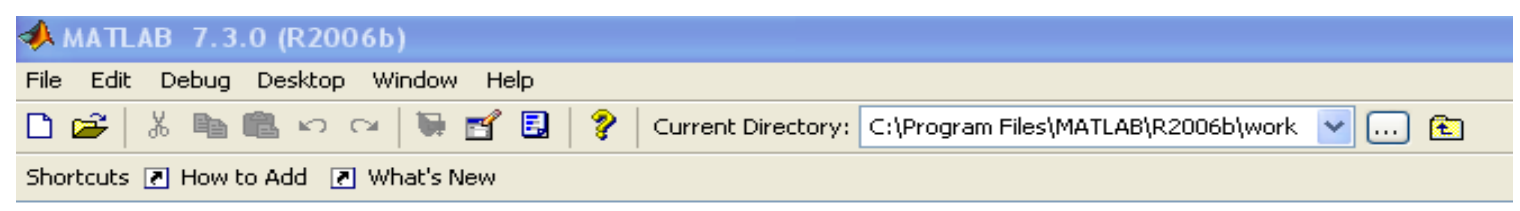

This is a Classroom License for instructional use only. Research and commercial use is prohibited.

To get started, select MATLAB Help or Demos from the Help menu.

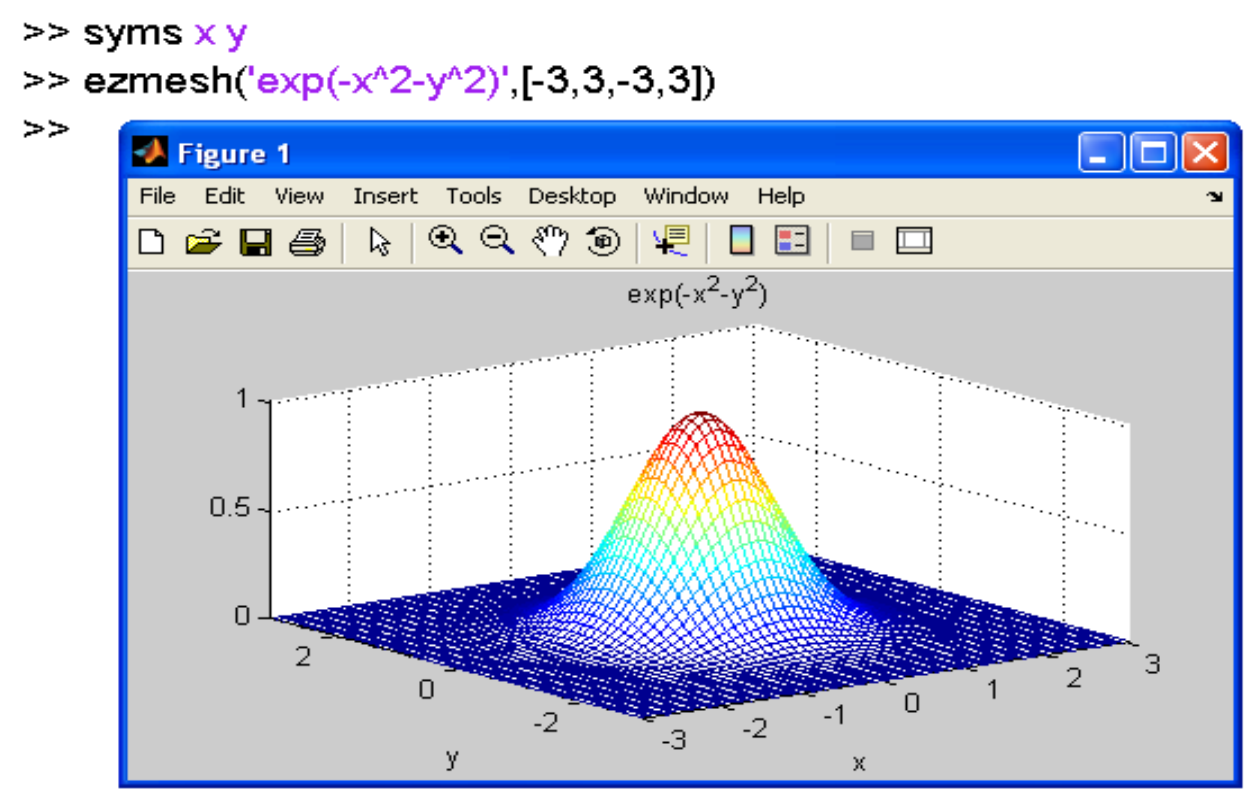

Figure 17a Plot of the two-variable function (1) 


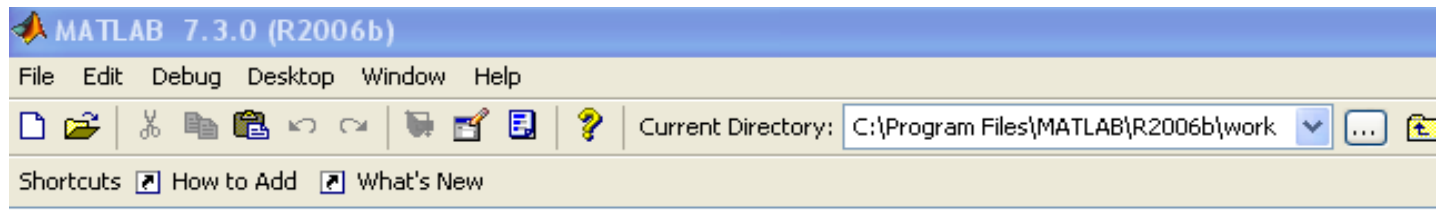

This is a Classroom License for instructional use only. Research and commercial use is prohibited.

To get started, select MATLAB Help or Demos from the Help menu.

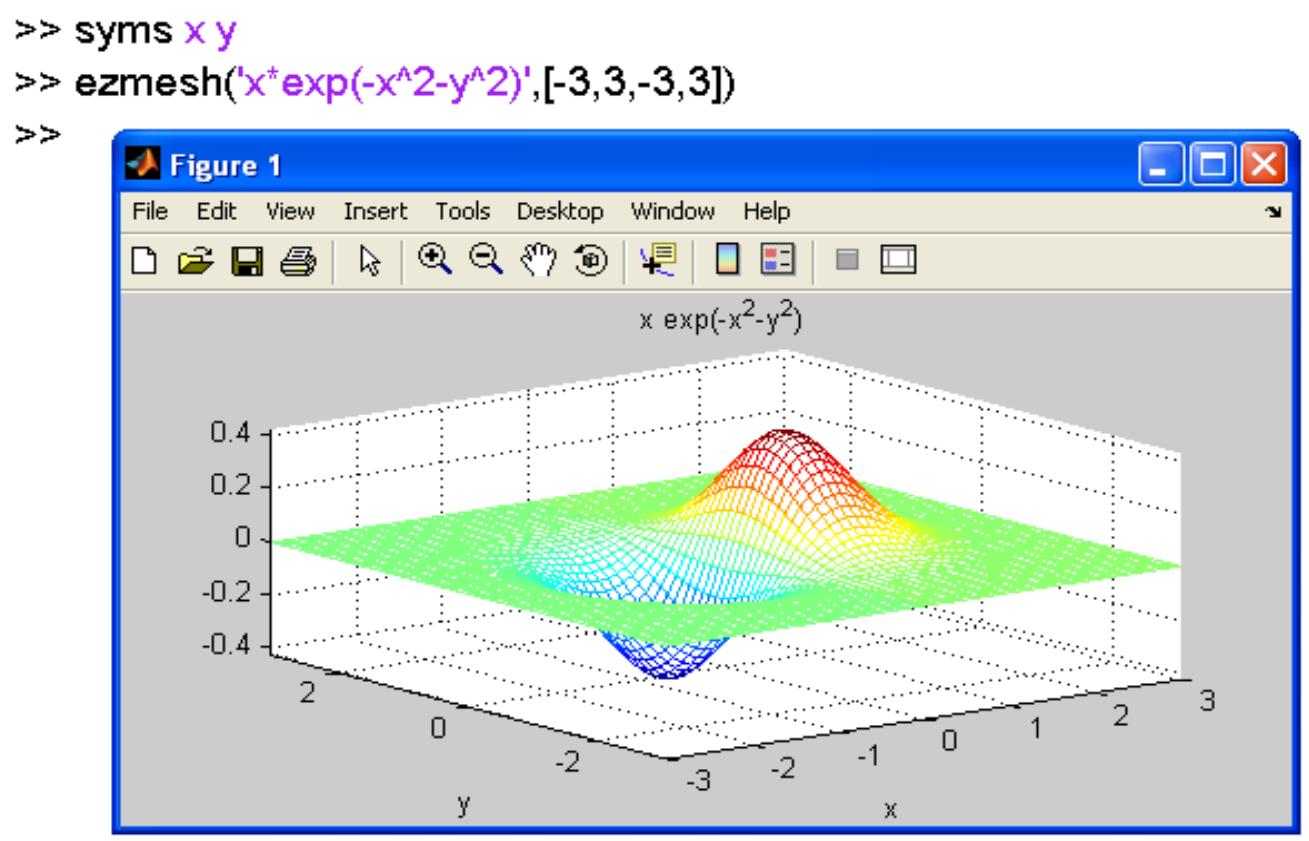

Figure 17b Plot of the two-variable function (2)

\subsubsection{Partial derivatives}

Example 2.11. Find the partial derivatives of the following functions.

(1) $f(x, y)=x^{2}+y e^{x}-y^{2}$;

(2) $g(x, y, z)=2 x^{2}+x y^{2}-3 x z^{2}$.

The MATLAB solutions to (1) and (2) are given in Figure 18a and Figure 18b, respectively. The results in Figure $18 \mathrm{a}$ and Figure $18 \mathrm{~b}$ show that

$$
\begin{aligned}
& \frac{\partial f}{\partial x}=2 x+y e^{x}, \quad \frac{\partial f}{\partial y}=e^{x}-2 y \\
& \frac{\partial g}{\partial x}=4 x+y^{2}-3 y z^{2}, \quad \frac{\partial g}{\partial y}=2 x y-3 x z^{2}, \quad \frac{\partial g}{\partial z}=-6 x y z
\end{aligned}
$$




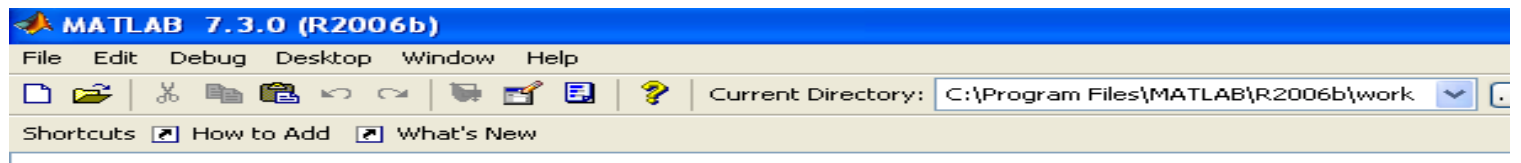

This is a Classroom License for instructional use only.

Research and commercial use is prohibited.

To get started, select MATLAB Help or Demos from the Help menu.

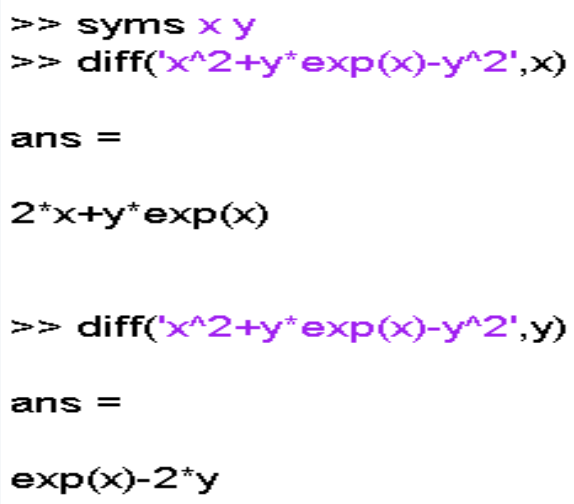

Figure 18a MATLAB solution to (1)

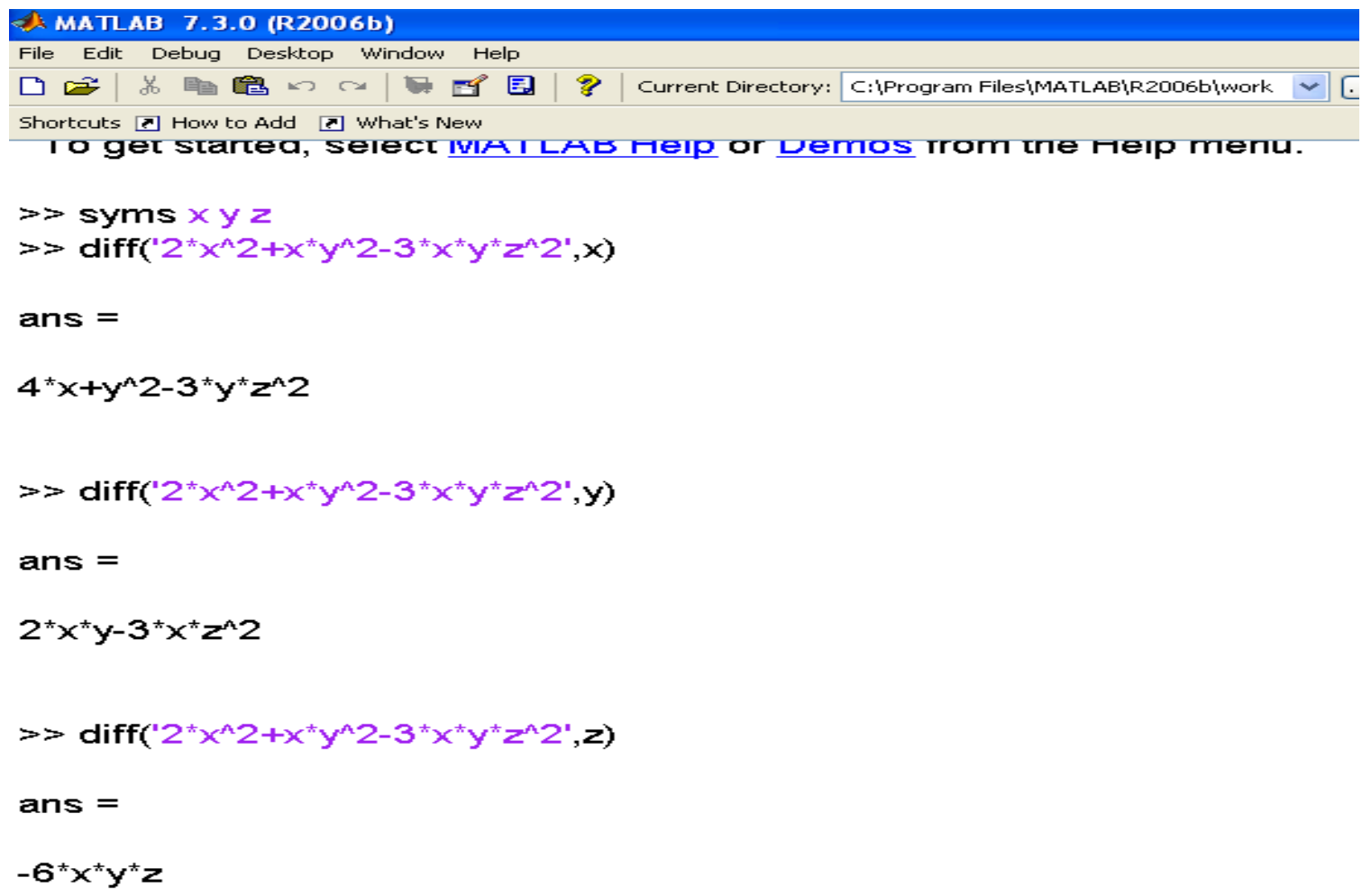

Figure 18b MATLAB solution to (2) 


\subsubsection{Optimization using Lagrange multipliers}

An optimal strategy for a quantitative business problem is usually subject to finite resources such as the finite budget. Therefore, it is a situation that optimization of an objective function (such as the profit function) is subject to certain constraints. The Lagrange multiplier method is usually employed to solve an optimization problem with constraints. See the following example.

Example 2.12. A manufacturing firm has budgeted $\$ 60,000$ per month for labor and materials. If $\$ x$ thousand is spent on labor and $\$ y$ thousand is spent on materials, and if the monthly output (in units) is given by

$N(x, y)=4 x y-8 x$,

How should the $\$ 60,000$ be allocated to labor and materials in order to maximize $N$ ? What is maximum $N$ ?

This is a maximization problem subject to the constraint $x+y=60$ (in thousands). The objective function using the Lagrange multiplier is given by

$f(x, y, z)=4 x y-8 x+z(x+y-60)$,

where $\mathrm{z}$ is the Lagrange multiplier. It is well-known that the optimal solution to $(x, y, z)$ is subject to:

$\frac{\partial f}{\partial x}=0, \quad \frac{\partial f}{\partial y}=0, \quad \frac{\partial f}{\partial z}=0$.

This is related to the computation of partial derivatives. The MATLAB solution is given in Figure 19.

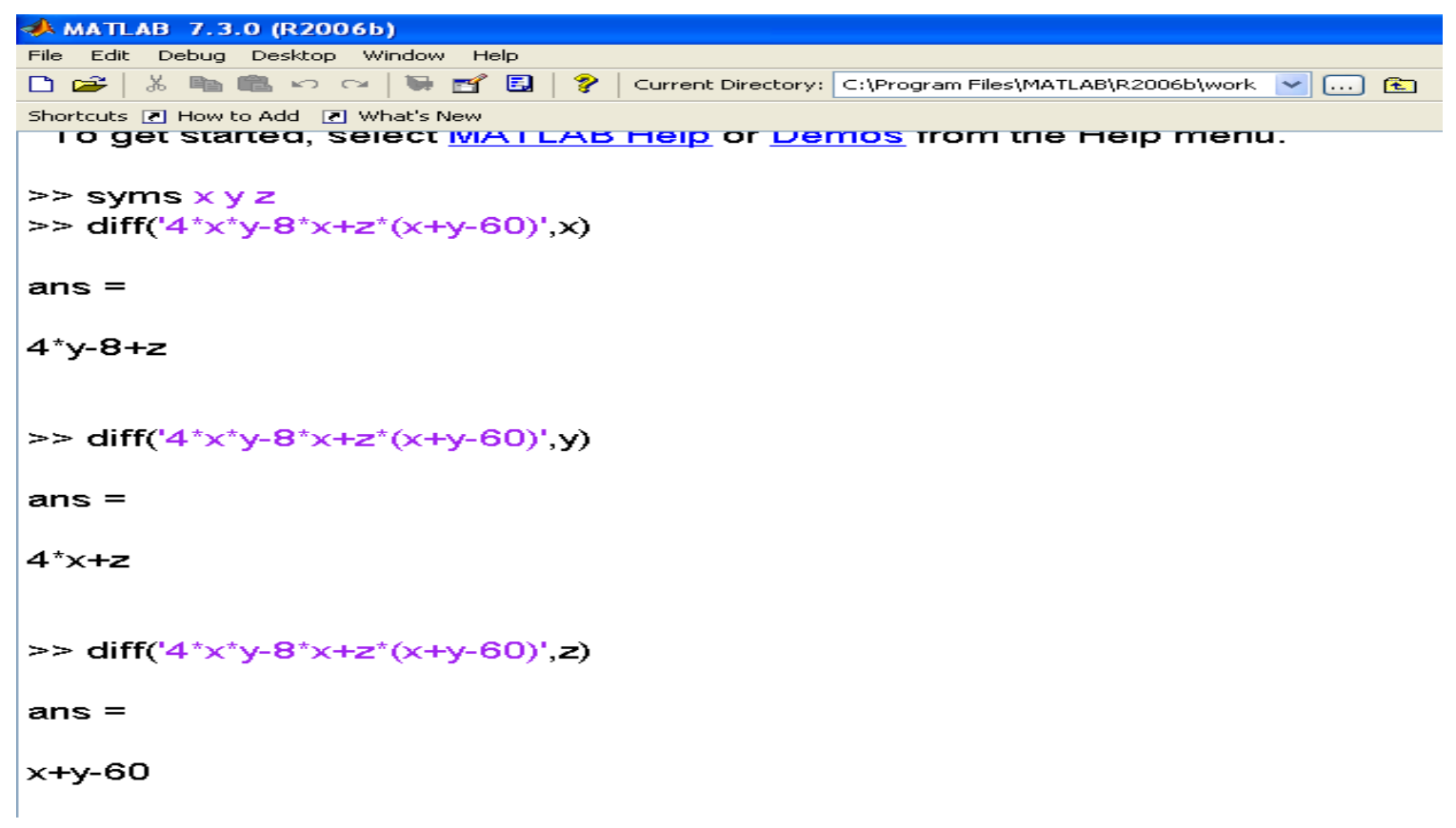

Figure 19a Computation of partial derivatives 


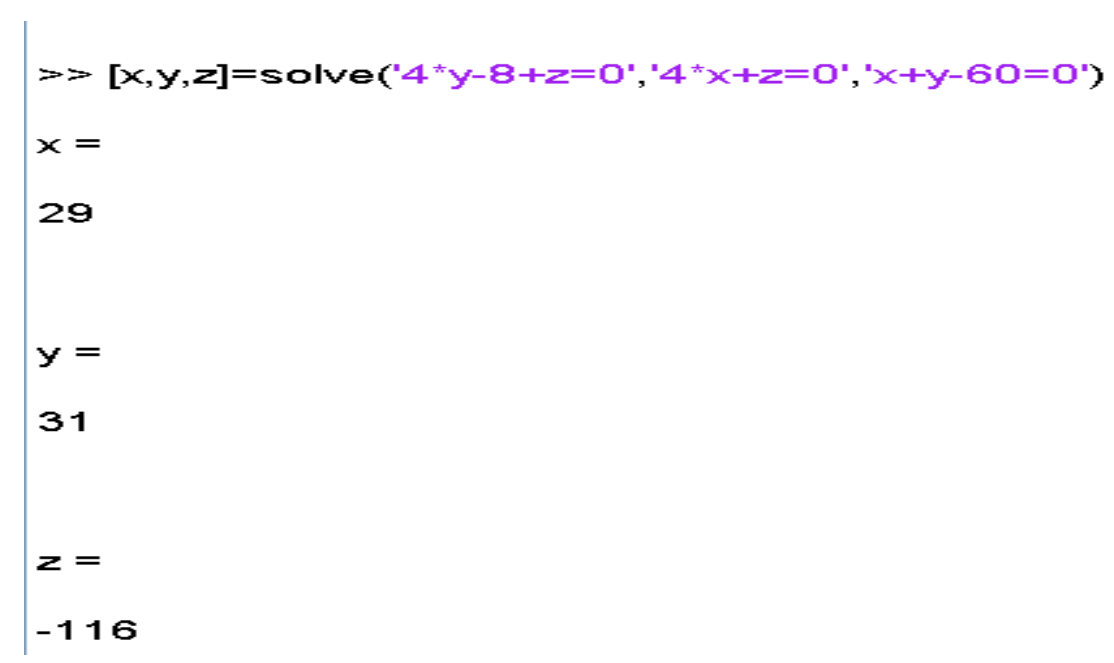

Figure 19b (Figure 19a continues) Optimal solution to $(x, y, z)$

Figure $19 \mathrm{~b}$ shows that the optimal solution to $(x, y, z)$ is $x=29, y=31$, and $z=-116$. Therefore, the maximum output is: $N=4 x y-8 x=4 \times 29 \times 31-8 \times 29=3364$.

In the practical point of view, the above solution to $(x, y, z)$ will be the best solution to maximizing the output function. In the theoretical point of view, it is necessary to check whether the locally optimal solution is really the best solution. This is related to the second order partial derivatives. We omit this step in practical business applications.

\section{CONCLUDING REMARKS}

MATLAB is a powerful numerical computation package. I $t$ can be used as an interactive mathematical shell and/or toolbox. In teaching of calculus-based business mathematics course at University of New Haven in the past few years, our experiences have consistently shown us that most freshmen in college of business do welcome the opportunity to learn the fundamental business concepts of cost minimization; profit maximization, as well as the quantitative techniques of searching for the optimal resource allocation solution in multivariate cases related to the real business world problems. Nevertheless, the difficulty is arisen when the concept of limits; derivative and integration rules and formulas in calculus are introduced; the majority of these students often struggle to find the correct numerical solution to the problem posed. This lack of algebraic ability and skills, we surmise, is due primarily to the previous uneven and the inadequate training and preparation. We hope that by teaching our students to utilize a dozen or so simple MATLAB function routines, as a supplementary skill-builder, our students can learn calculus-based business mathematics much quicker, better and easier.

What's more, It is also our expectation that the simple MATLAB function commands we have demonstrated in this paper will enable our students to avoid the trap of boggle down in the memorization of the fine detail of mathematical procedure and calculation rules; instead, to focus on the key objective of learning business mathematics in the first place -- to obtain, with the graphical illustrations on the side, quickly and easily the numerical solutions, and thus our student will be empowered to examine the big-picture setting. As a result, these students will be more likely to become better decision makers in facing the dynamic and ever-changing business challenges.

\section{REFERENCES}

1. Barnett, R. A., Ziegler, M. R., and Byleen, K. E. (2003). Applied Calculus for Business, Economics, Life Sciences, and Social Sciences. Prentice Hall.

2. Symbolic Math Toolbox User's Guide (2006). The MathWorks, Inc. (www.mathworks.com) 